\author{
دور الأكاء الشعوري في معالجة مشكلات ضغوط مناط العمل:

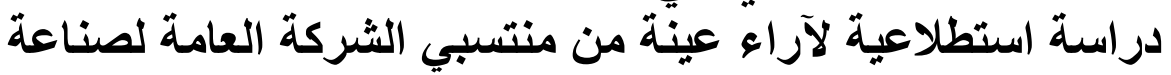 \\ الأدوية في نينوى منئي \\ الدكتورة ميسون عبدالله احمد \\ مدرس - قسم إدارة الأعمال \\ كلية الإدارة والاقتصاد - جامعة الموصل
}

Alfahed_69@yahoo.com?

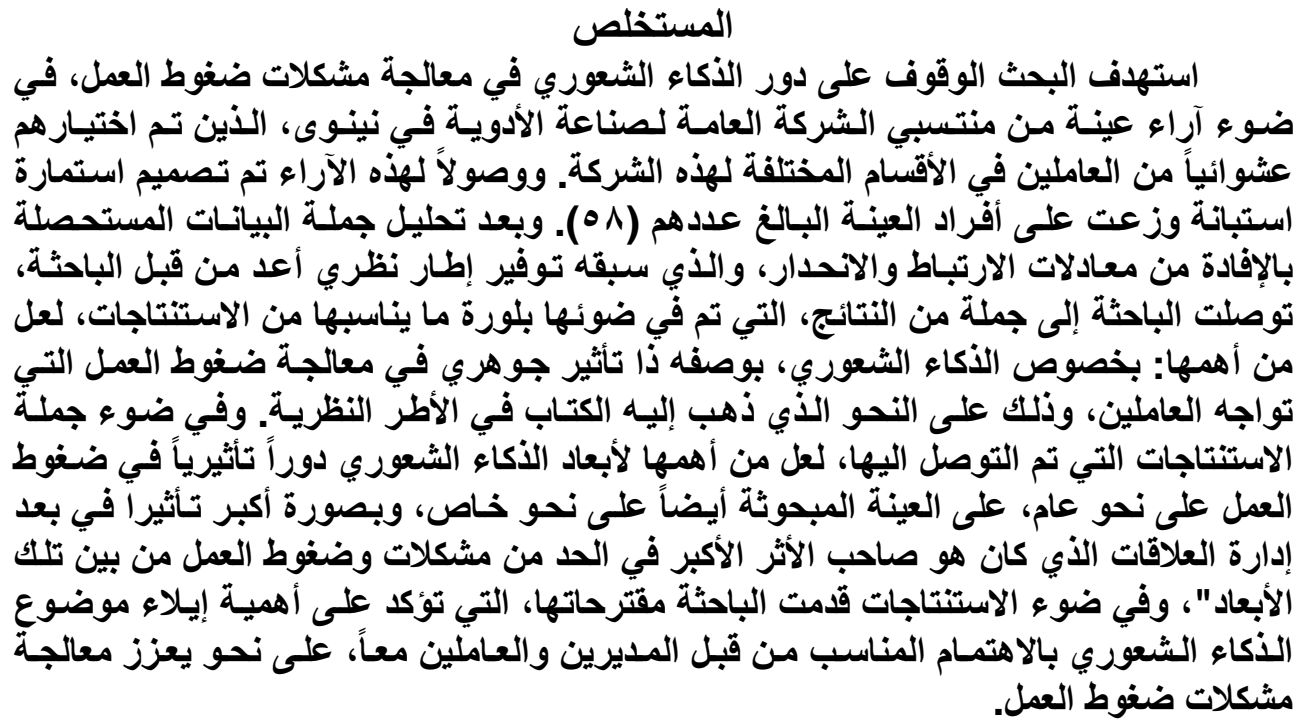
الكلمات المفتاحية: الأكاء الثعور، الأكاء الثعوري، ضغوط العمل، نماذج ضغوط العمل. 


\title{
The Role of Emotional Intelligence in Dealing with the Problems of Work Pressures: A Pilot Study of the Opinions of a Sample of Employees in the General Company for the Pharmaceutical Industry in Nineveh
}

\author{
Maysoon A. Ahmad (PhD) \\ Lecturer \\ Department of Business Administration \\ University of Mosul
}

\begin{abstract}
The present research was to identify the role of emotional intelligence in dealing with the problems of work pressures, in the light of the opinions of employees of the State Company for Drugs Industry in Nineveh, who had been randomly selected workers in the various sections of this company. This consensus form was designed as questionnaire premised for this purpose, and distributed to the respondents, who numbered (58). After analyzing the data, inter withdrawn to benefit from the link and regression equations, which was preceded provide a conceptual framework prepared by the researcher. The researcher found, among other results, that there has been crystallizing in the light of the appropriate conclusions, perhaps the most important: the possibility to say about emotional intelligence as a significant impact in addressing the work pressures faced by workers, and so on as the view of the book in the theoretical frameworks of organizational behavior since the twenties of the last century. In the light of conclusions among the most important of the dimensions of emotional intelligence Tothrea role in the work stress in general, and applies to the sample examined, and also more influential in the post-management relations, who was the greatest impact in reducing the problems and pressures of work among these dimensions, "In the light of the conclusions presented, researcher proposals emphasized the importance of paying attention to the subject of emotional intelligence by the appropriate managers and staff together, a way that promotes address the problems of pressure of work.
\end{abstract}

Key Words: Emotion, Intelligen, Emotional Intelligence, Work Pressures, Model of Work Stress.

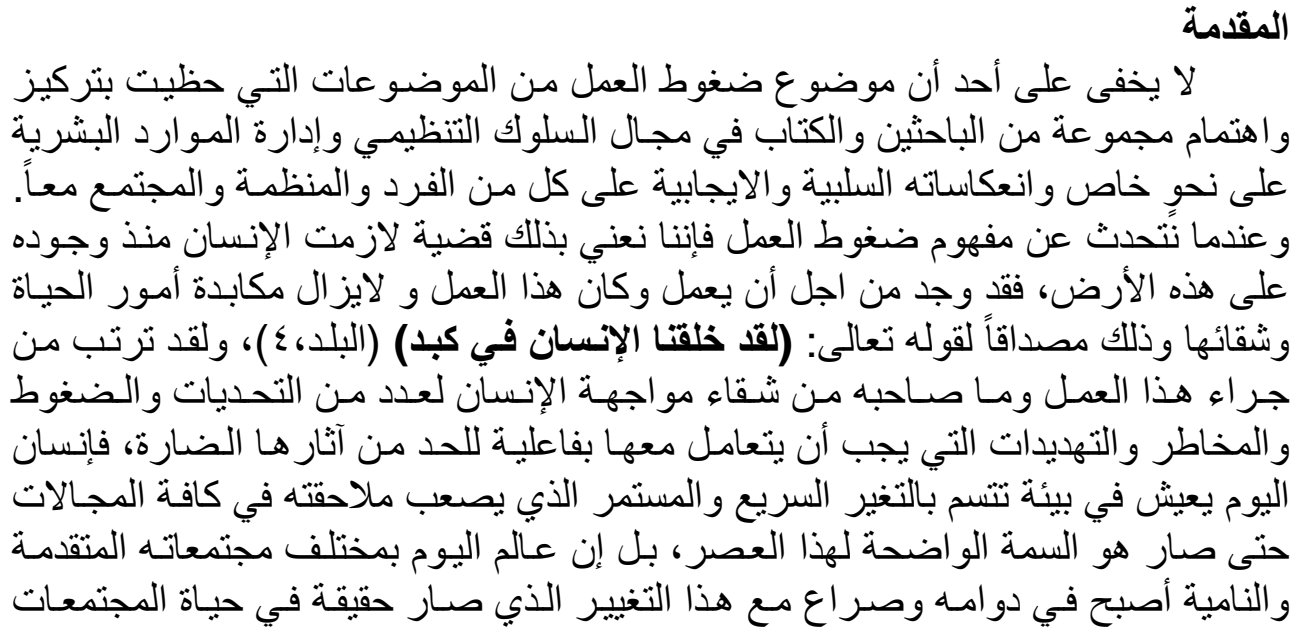




\section{[av] أحمد}

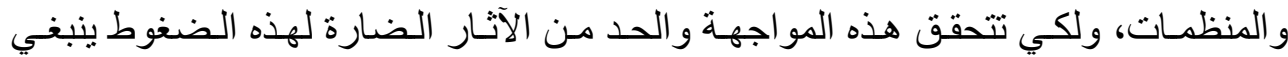

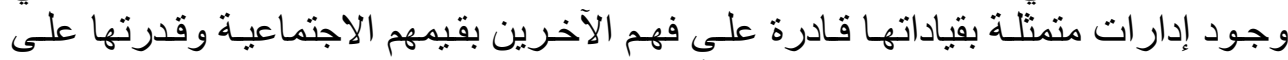

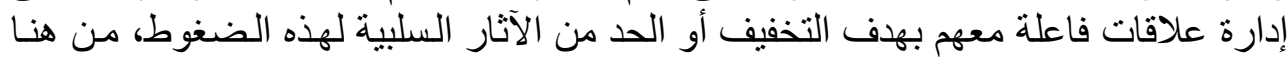

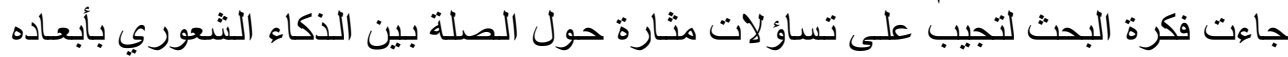

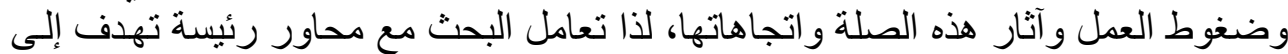

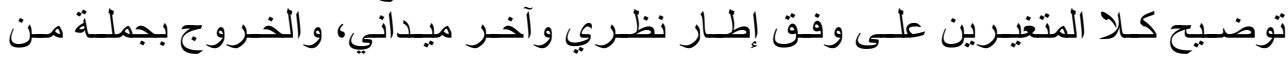

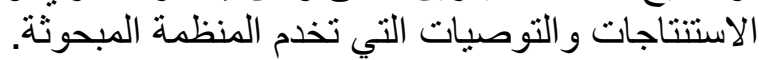

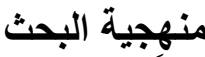 \\ أولاً مشكلة البحث البه}

تمهيداً للمعالجة البحثية لما ورد في مقدمة البحث، سعت الباحثة نحو إعادة صياغتها كمشكلة له من خلال التساؤلات الآتية:

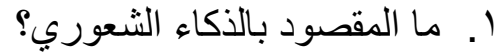

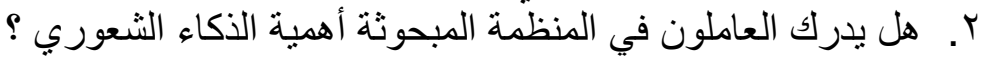

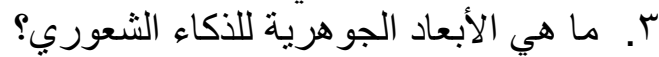

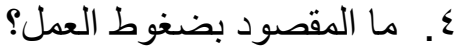

×. هل يدرك العاملون في المنظمة المبحوثة ماهيتة ضغوط العمل التي يو اجهونها؟

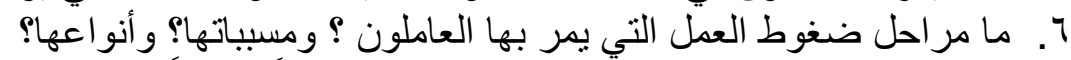

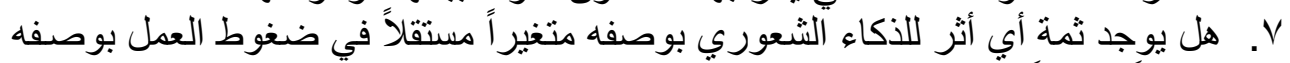
متغير اً معتمداً.

\section{ثانياً أهمية البحث وأهد(فه}

تبرز أهمية هذا البحث من أهمية أهدافه بوصنه أهنها تسعى نحو التعريف بمفاهيم الذكاء الثعوري، وضغوط العمل و العلاقة البحة بينها. وحيث أنها تبدو نظرية وميدانية، لذا يمكن القول إن أهميته ستحدد على النحو الآتي:

الأهمية النظرية

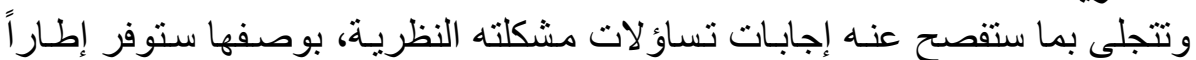

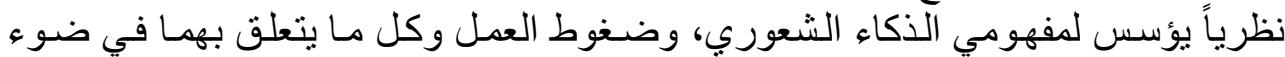

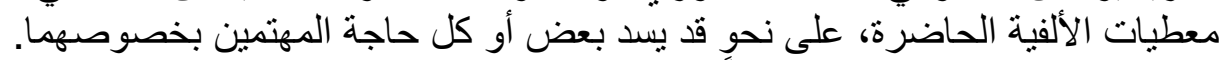
الأهمية الميدانية الأنفية

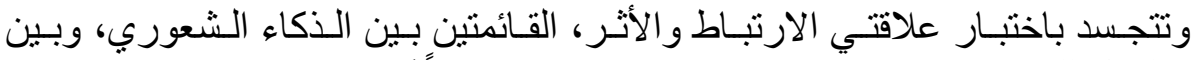

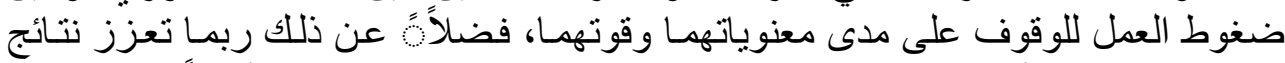

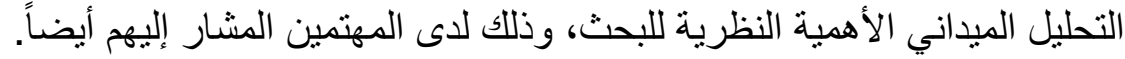

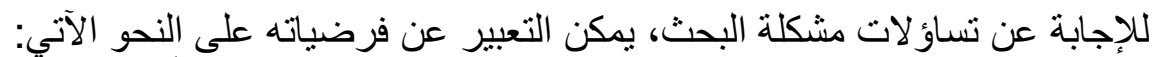

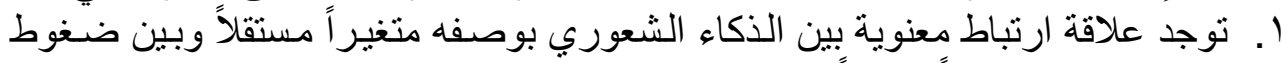
العمل بوصفه متغيراً معتمداً. 


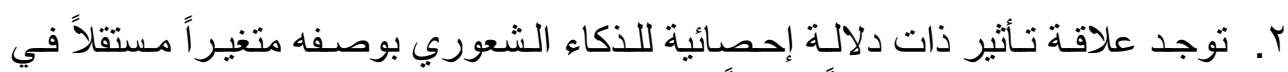

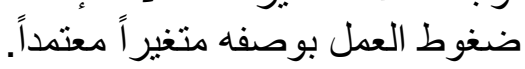

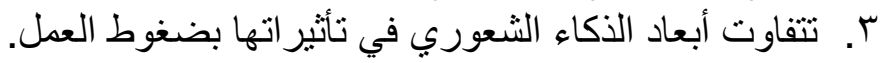

رابعاً- مجتمع البحث وعينته تمثل مجتمع البحثث بـ (الشركة العامـة لصناعة الأدويـة في نينوى) بوصفها حدوده

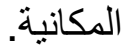
أما فيما يخص عينته، فقد تم اختيار ها على نحو عشو ائي من فئة العاملين في الأقسام

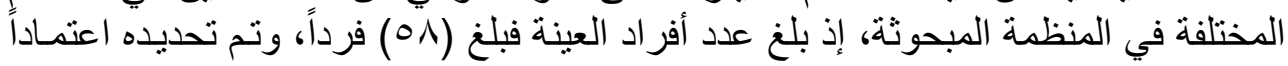

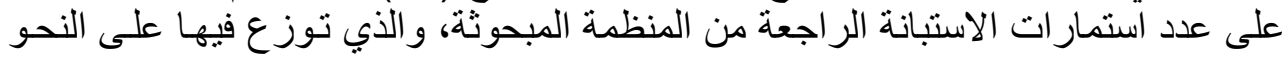

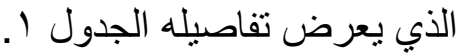

\begin{tabular}{|c|c|c|c|c|}
\hline \multicolumn{5}{|c|}{ عدد استمارات الاستبانة الموزعة والراجعة } \\
\hline في العينة التمثيل & عدد الاستمارات & عدد الاستمارات & سالشركة العامة لصناعة الأدوية & ت \\
\hline $1 \cdots$ & 10 & 10 & قسم قطرات العيون. & 1 \\
\hline 94 & $1 \varepsilon$ & 10 & قسم الحبوب & $r$ \\
\hline $1 \ldots$ & 10 & 10 & قسم المر اهم & $r$ \\
\hline 94 & $1 \leq$ & 10 & قسم المحاليل الوريدية & $\varepsilon$ \\
\hline $9 V$ & 01 & 7. & موع & \\
\hline
\end{tabular}

\section{خامساً- منهج البحث وتقاناته}

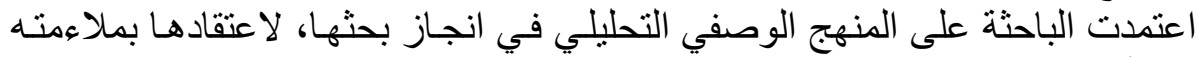

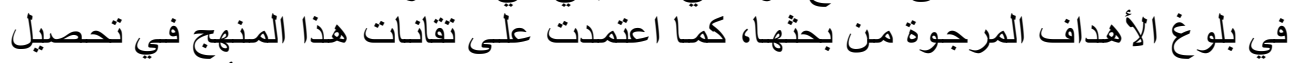

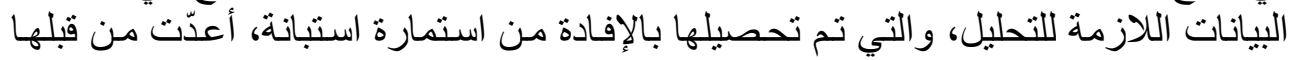

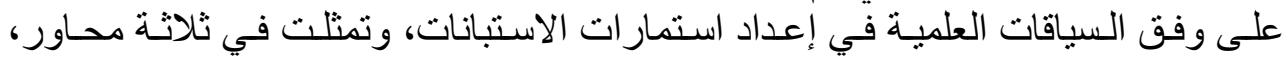

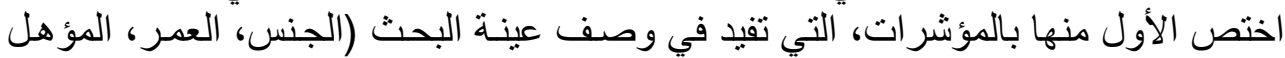

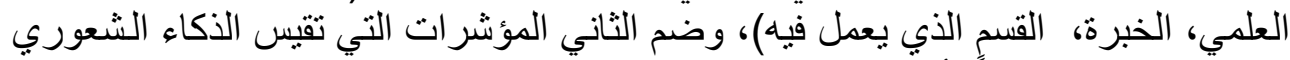

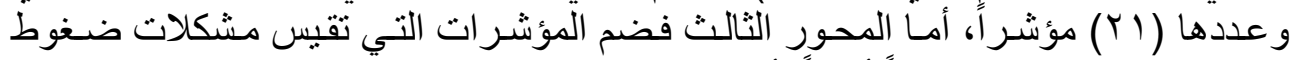

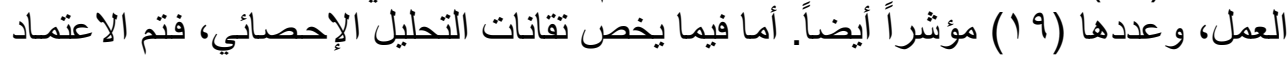

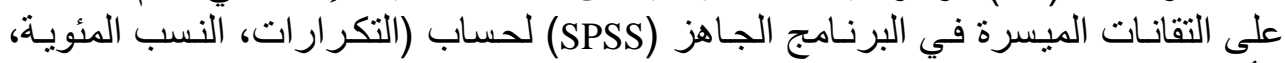

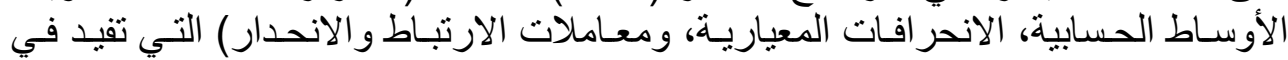
إنجاز الإطار الميداني للبحث. الإطار النظري الإز النار

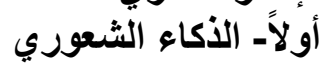

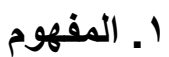




\section{[99] أحمد}

قبل الدخول في توضيح مفهوم الذكاء الشعوري (Emotional Intelligence) لابد من كن

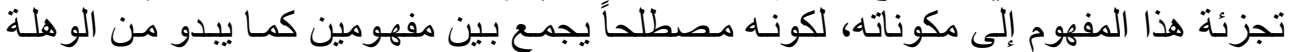

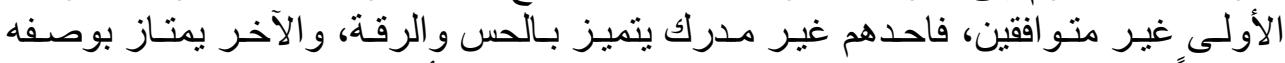

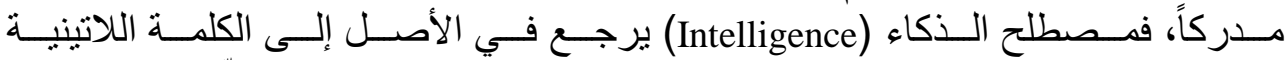

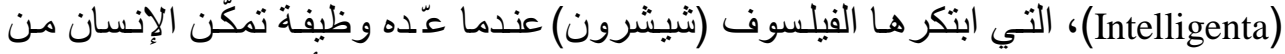

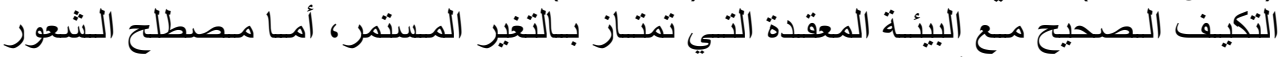

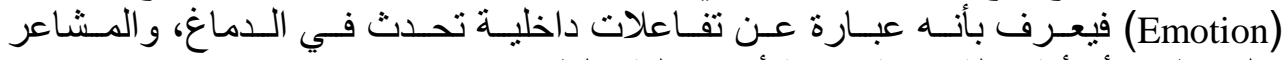

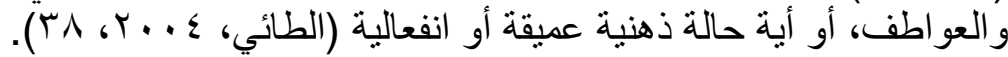

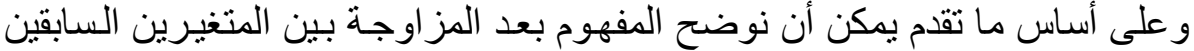

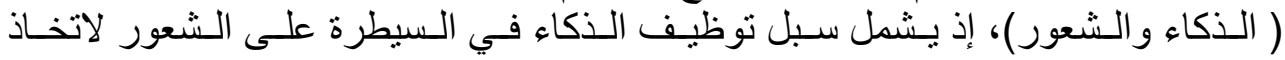

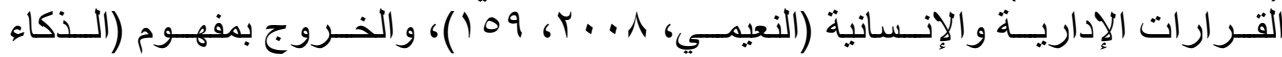

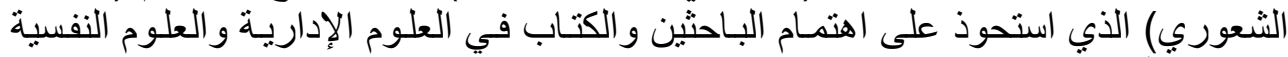

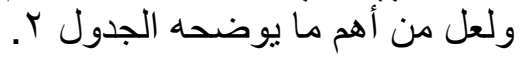

\begin{tabular}{|c|c|}
\hline المفهوم & الباحث والسنة \\
\hline 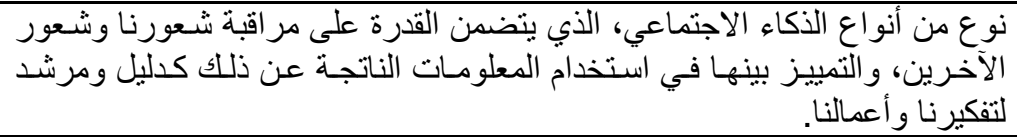 & $\begin{array}{c}\text { Mayer and } \\
\text { Salovey,1990,189 }\end{array}$ \\
\hline 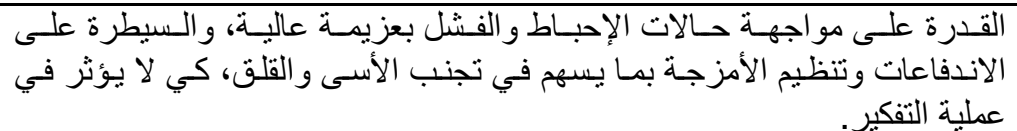 & Goleman,1995,34 \\
\hline للنجاح في اجتياز منطلبات القدرات والقابليات غير مدركة، و المقررات التي تؤثر على قابلية الفرد & Bar-on, 1997,14 \\
\hline المعلورة على التقييم و الإدر الك الدقيق للشعور و القات اكتساب و تقديم المعرفة، من خلال تلكي & $\begin{array}{c}\text { Mayer and } \\
\text { Salovey,1997,10 }\end{array}$ \\
\hline هذه المشابلة لمعرفة معاني المشاعر، و استيعاب العلاقة بينها، وبين فهم المعلومات عن & $\begin{array}{c}\text { Mayer and } \\
\text { Salovey,1999,269 }\end{array}$ \\
\hline الحياة. مجموعة مـن القدر ات غير المدركة، التي تؤُثر في قدراتتا مـن اجل النجـاح في & $\begin{array}{l}\text { Orma,Cannon,2000, } \\
19\end{array}$ \\
\hline القدرة على تنظيم الشعور ، والتأثنير في الآخرين. & Daft,2001,102 \\
\hline 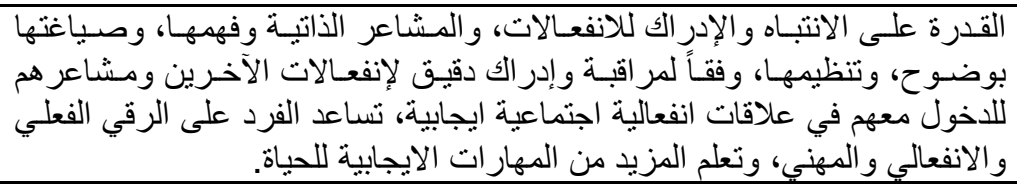 & عثمان، Y ... Y I \\
\hline
\end{tabular}

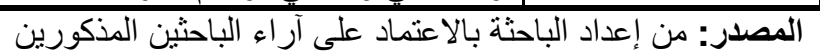

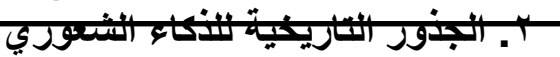

يمكننا القول بان الذكاء الثعوري ليس بالمفهوم الجديد، بقدر مـا هو امتداد لمصطلح

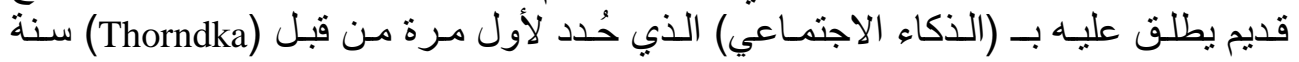




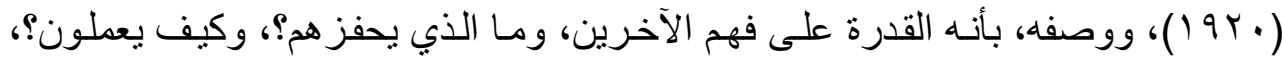

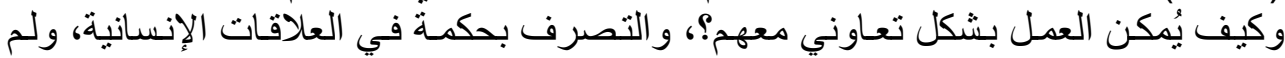

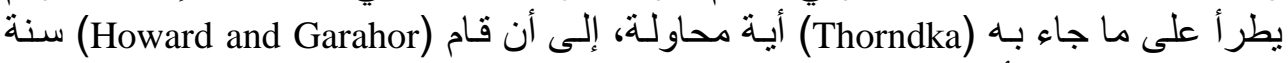

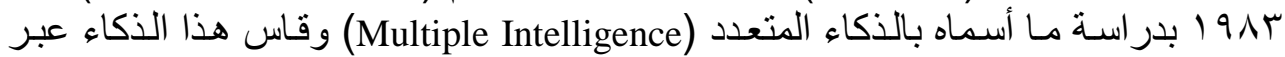

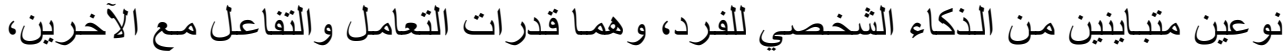

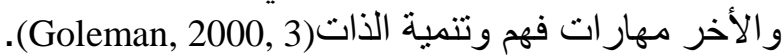

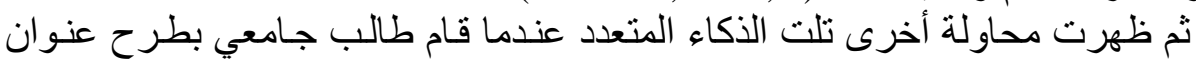

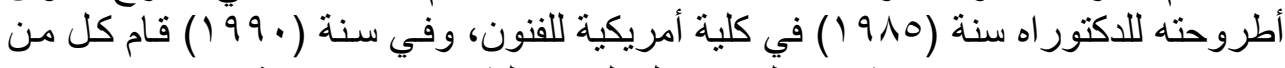

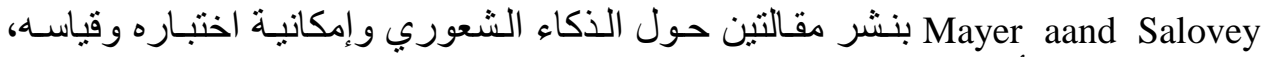

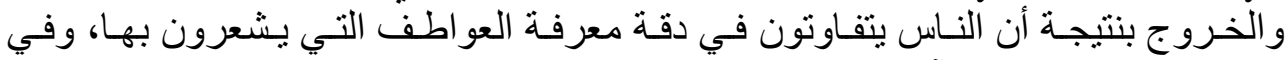

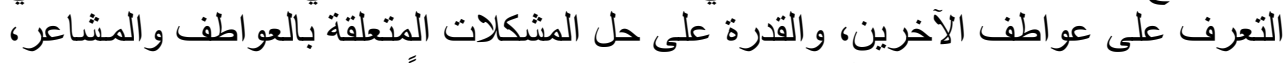

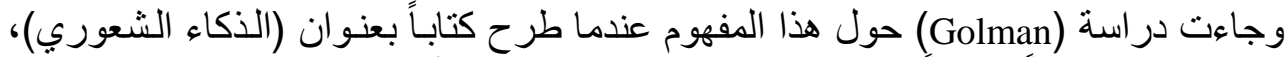

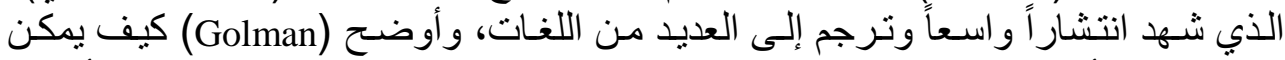

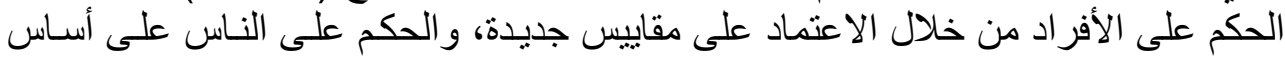
كيف أنت ذكي؟ بد الافر من كن كم أنت ذكي؟ (Curre, 2009, 7) (Brust, 2001, 3).

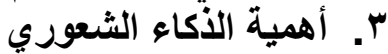
تتمثل أهمية الذكاء الثعوري بالعديد من الدلالات التي جاء بها الباحثون والكتاب

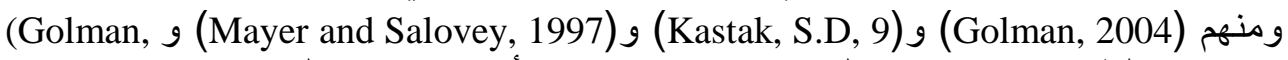

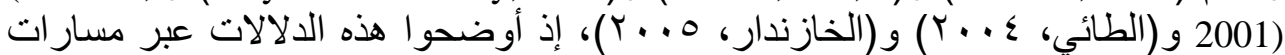

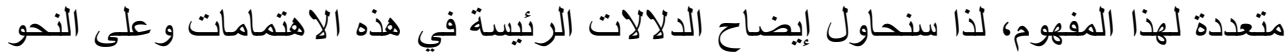

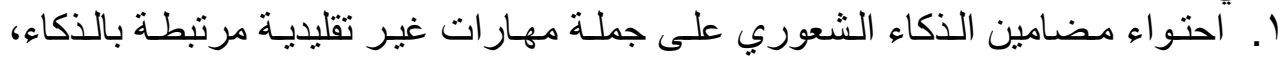

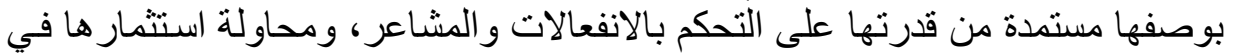
تحقيق الأداء الأفضل، و اتخاذ القرار ات الداعمة للعمل عبر فهم الذات وتوجيـه السلوك

(Mayer and Salovey, 1997, 29-31)

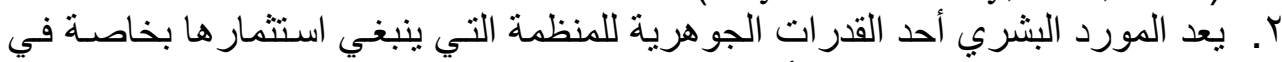

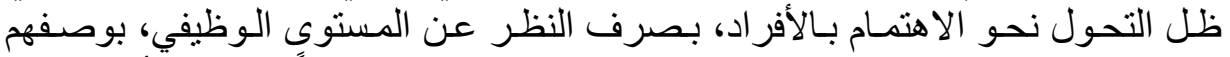

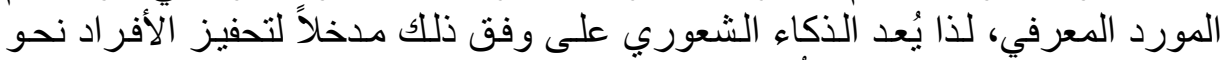

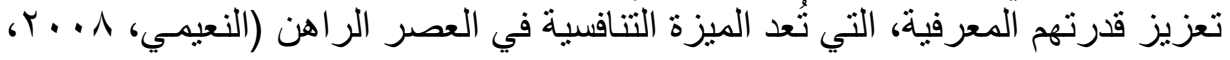

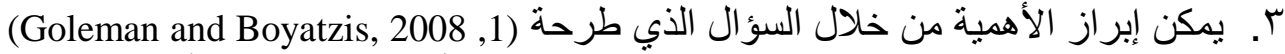

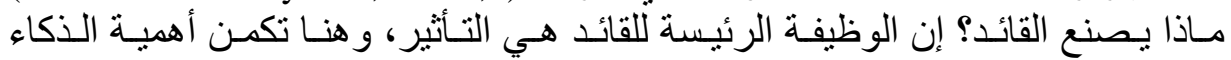

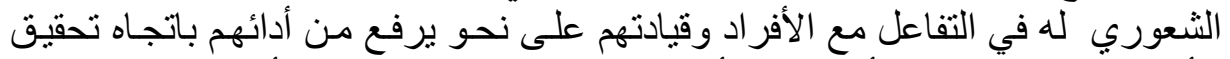

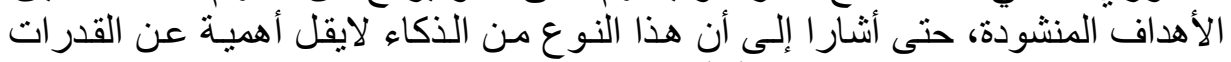

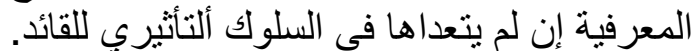

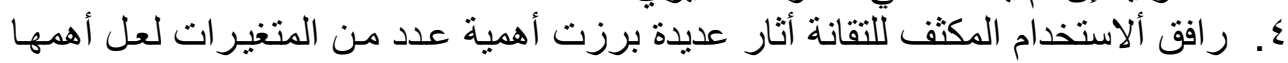

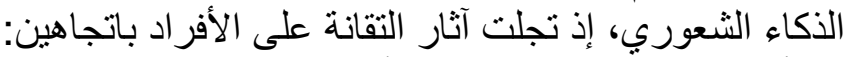

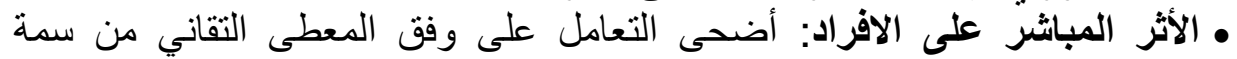

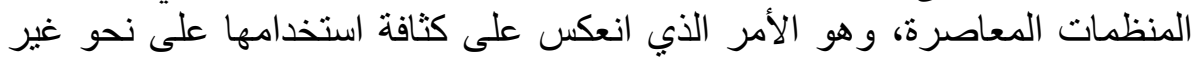




\section{أحمد] [1.1}

مسبوق وتأثير ذلك على الجوانب الثعورية للعاملين، ولعل غضب الأفراد كنتيجة

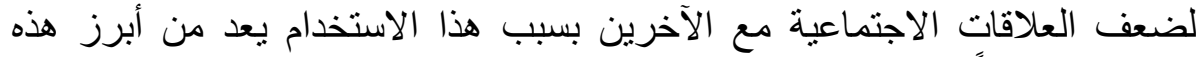

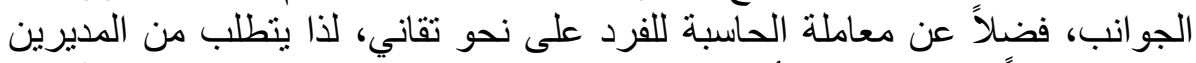

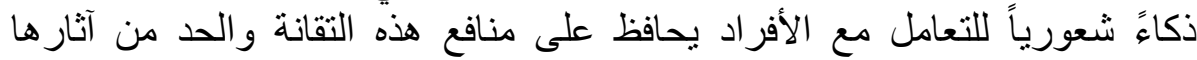
• الآثار غير المباثرة على الأفراد (الهيكلية): انعكس تضمين التقانة في الأعمال

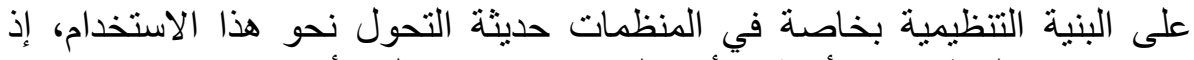

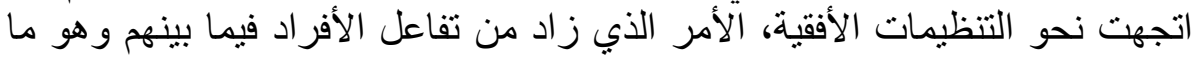

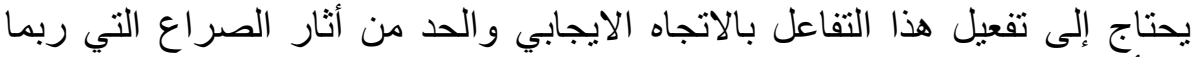

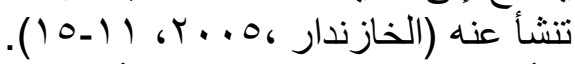

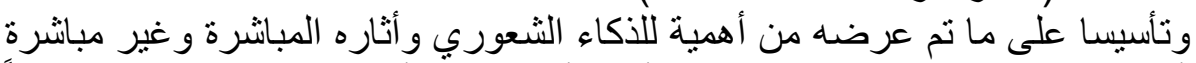

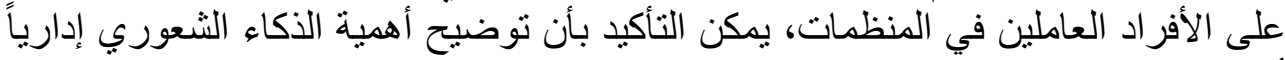

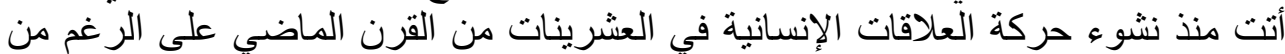

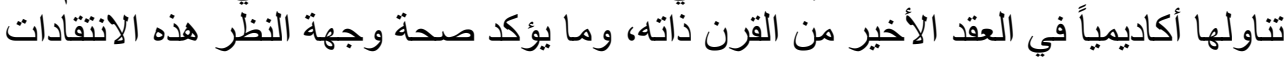
التي وجهت لمدرسة الإدارة العلمية.

•ـ النماذج المفسرة للأكاء الثعوري

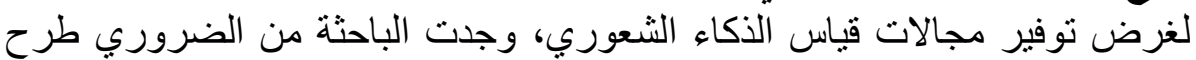

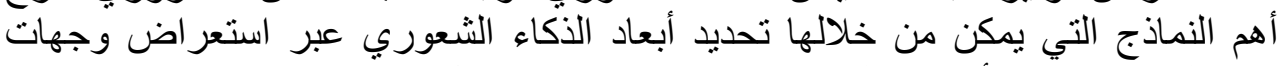

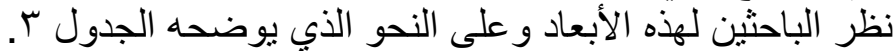

\begin{tabular}{|c|c|c|c|}
\hline 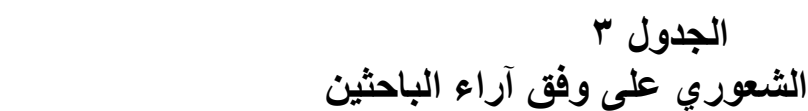 & أبعاد الذكاء & & \\
\hline الأبعاد الفرعية & البعد الرئيسي & الباحث/السنة & $ت$ \\
\hline التدقيق الدقيق للذات،ضبط ألذات،تقييم ألذات. & فهم الذات & \multirow{5}{*}{$\begin{array}{l}\text { Golman } \\
1990\end{array}$} & \multirow{5}{*}{.1} \\
\hline الذاتية. الذبة الذاتيـة، التكيف الذاتي مـع التغيير، الإبـداع الذاتي،الجـدارة & التعليم الذاتي & & \\
\hline الانجاز، الدو افع، الالتزام، المبادرة، التفاؤل. & التحفيز & & \\
\hline فهم الآخرين،تطوير الآخرين، التوجه بالخدمات نحو الآخرين. & الاعتناق العقى & & \\
\hline الصتأثير في الآخرين، الاتصال مـع الآخرين، حل المشكلات،حل & 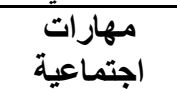 & & \\
\hline 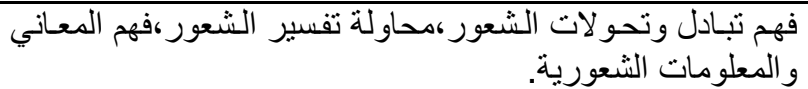 & الثعوري & \multirow{4}{*}{$\begin{array}{l}\text { Mayer and } \\
\text { Salovey, } \\
199 \mathrm{~V}\end{array}$} & \multirow{4}{*}{ r } \\
\hline بين التعبير الثُعورية. لإظهار الثعور، إدراك الشعور الذاتي،التمييز & الثُإدراك & & \\
\hline 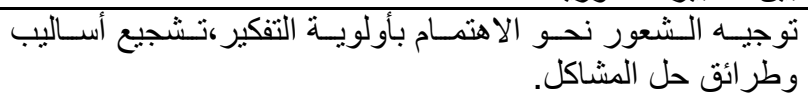 & الثعوري & & \\
\hline 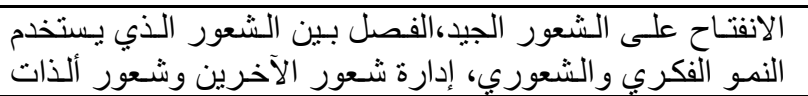 & الثعورية - الإداة & & \\
\hline
\end{tabular}




\begin{tabular}{|c|c|c|c|}
\hline الأبعاد الفرعية & البعد الرئيسي & الباحث/السنة & ت \\
\hline ،تحسين الشعور الايجابي واستبدال وتعديل الشعور السلبي. & & & \\
\hline 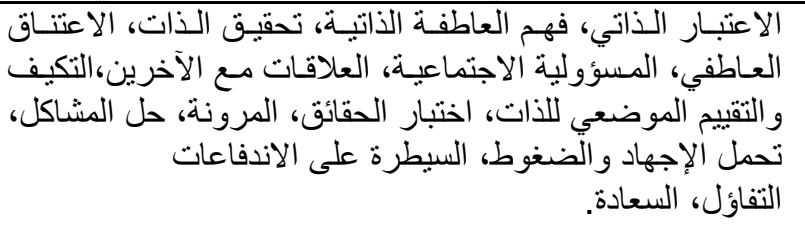 & & $\begin{array}{l}\text { Bar-On } \\
199 \vee\end{array}$ & r \\
\hline فهم ألذات، تقييم ألذات، الثقة بالنفس. & 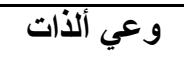 & \multirow{4}{*}{$\begin{array}{l}\text { Golman } \\
199 \wedge\end{array}$} & \multirow{4}{*}{$\varepsilon$} \\
\hline الرقابة الذاتية، المبادرات. & 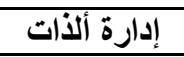 & & \\
\hline العمل الجماعثير في الآخرين، الاتصالات الآخرين وتطوير هم، بناء الروابط وفرق & اجتمارعية & & \\
\hline الاعتناق العاطفي، الوعي ألمنظمي، التوجه الاجتماعي. & الاجتماعي & & \\
\hline
\end{tabular}

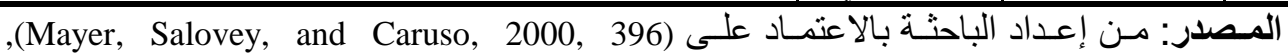

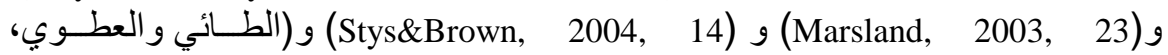

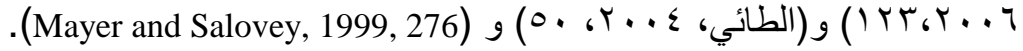

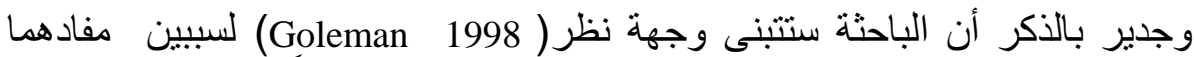

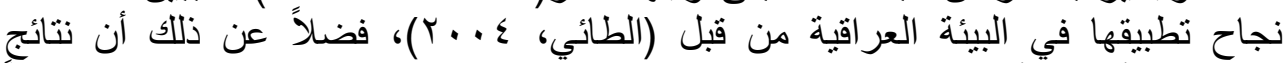

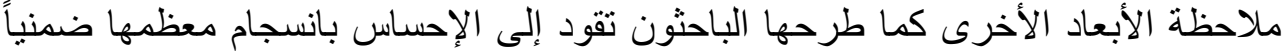
معه، ومن أجل إيضاح هذه الأبعاد بشيء من التفصيل سوف التهاد نتناولها على النحو الآتي :(Goleman, 1998,132) ا. فهم الذات: وتعني القدرة على إدراك الأمزجة، وفهم الشعور الخاص بـالفرد الذي يؤثر

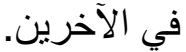
r. إدارة الذات: وتعني القدرة على رقابة أو إعادة توجيه الأمزجة و الاندفاعات والاستعداد

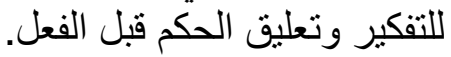

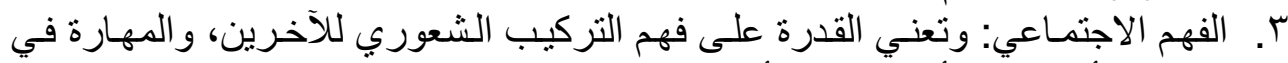

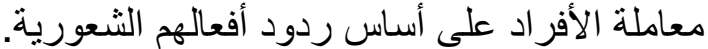

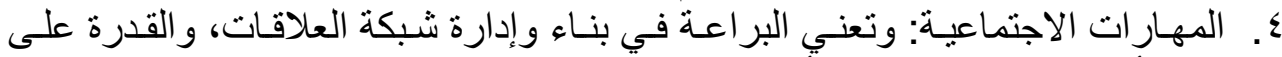
إيجاد أرضية مشتركة لبناء الألفة مع الآخرين.

\section{ثُانياً- ضغوط العمل

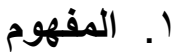

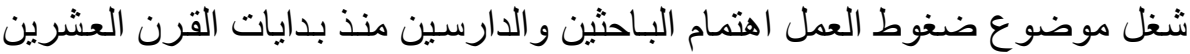

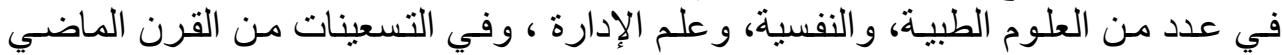

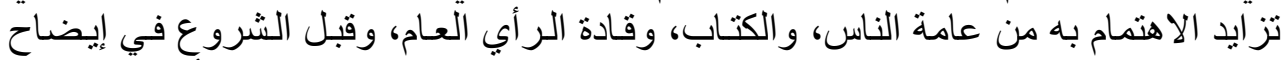

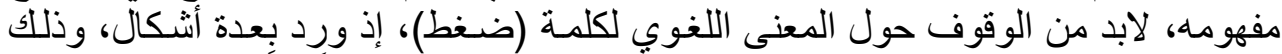

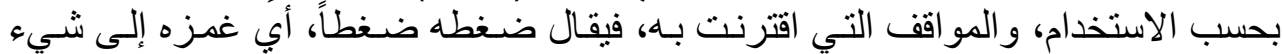

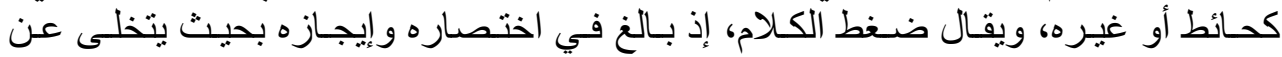




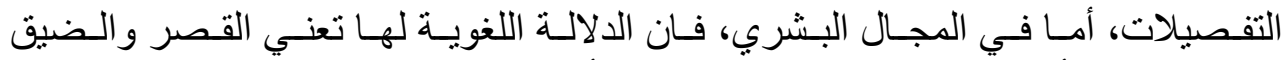

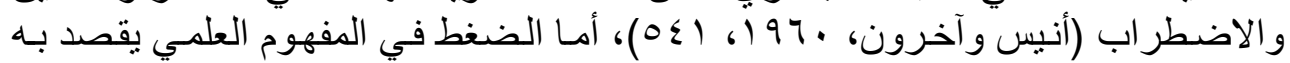

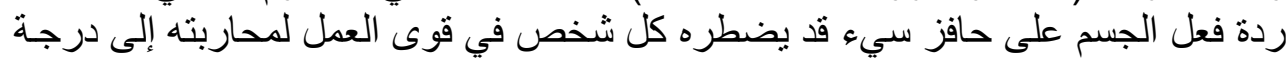

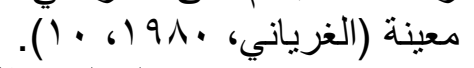

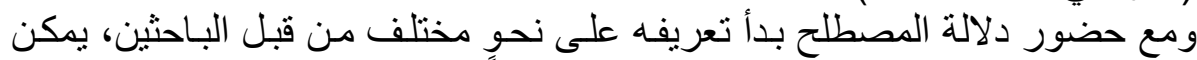

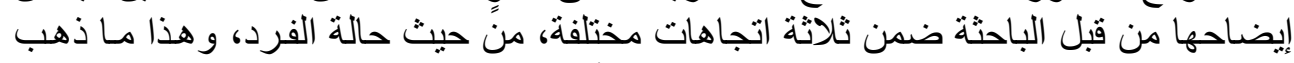

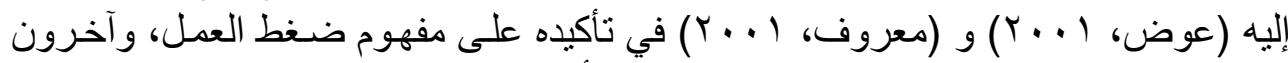

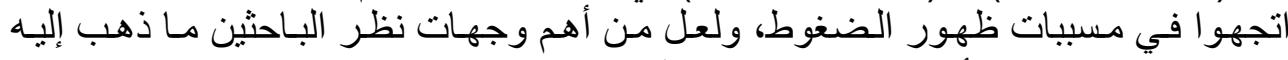

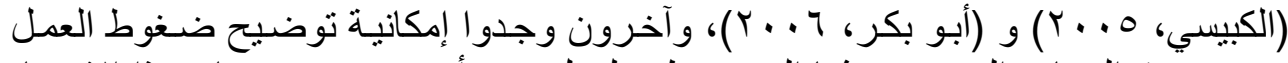

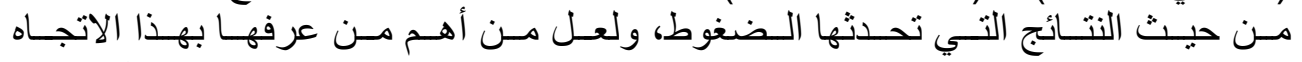

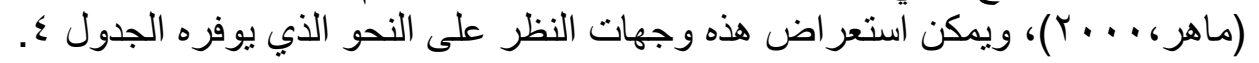

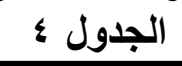

\begin{tabular}{|c|c|}
\hline \multicolumn{2}{|c|}{ مفاهيم ضغوط العمل على وفقى اراء الباحتيني } \\
\hline 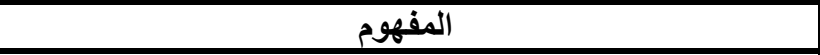 & الباحث والسنة \\
\hline 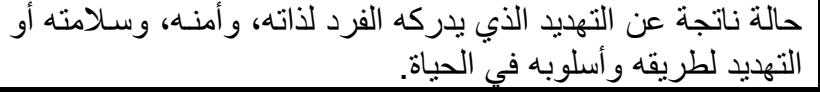 & 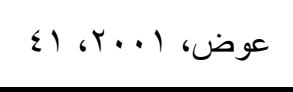 \\
\hline 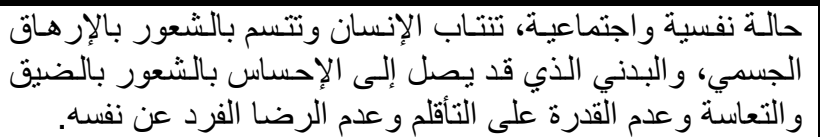 & 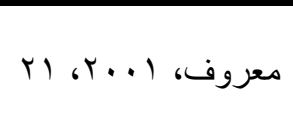 \\
\hline 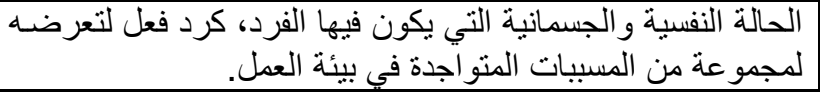 & أبو بكر، T... T، r TH \\
\hline 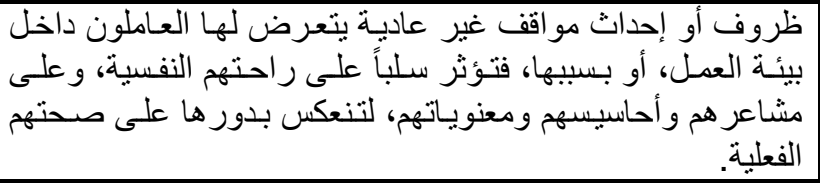 & 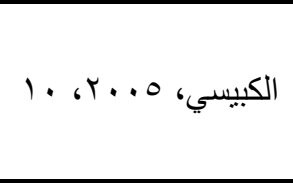 \\
\hline 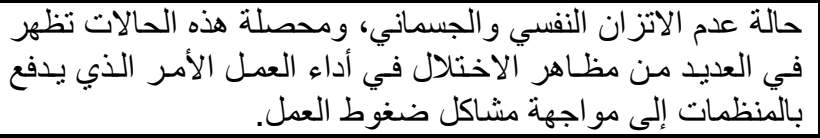 & 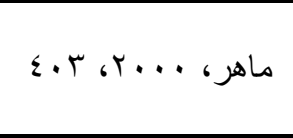 \\
\hline والقوئف الخارجية التي تسبب تشويها مادياً في هيكل الجسم أو تعطيل & 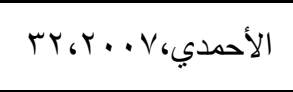 \\
\hline
\end{tabular}

المصدر: من إعداد الباحثة بالاعتماد على المصادر المشار اليها في الجدول

يمكن بيان أهم المر احل التي تمر بها حالة عدم التوازن لاى الفرد المسببة للوصول

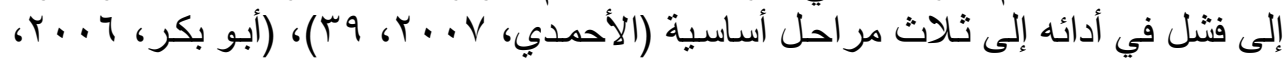

المرحلة الأولى يطلق عليها بمرحلة الإنذار المبكر (The Alarm Reaction) وهي وليكي

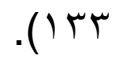

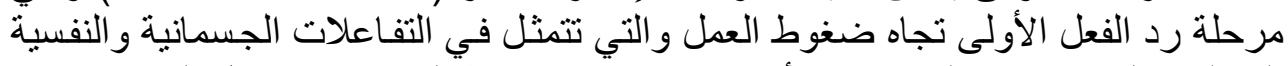

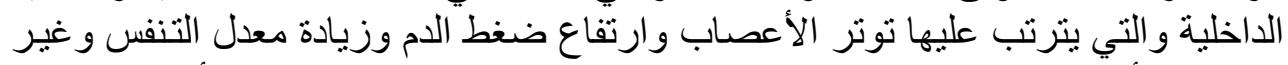

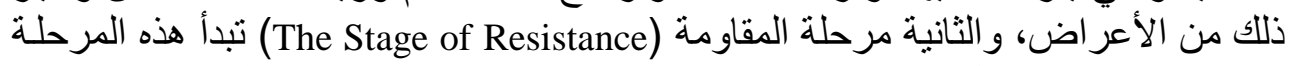

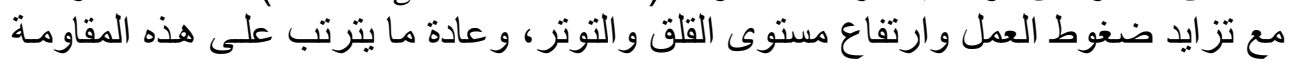




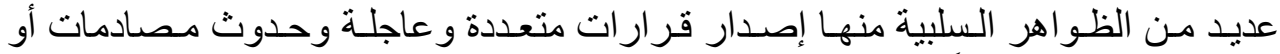

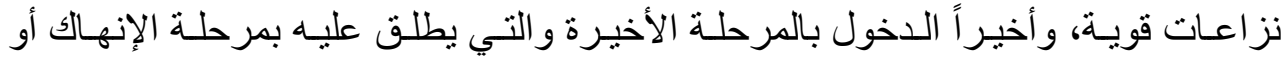

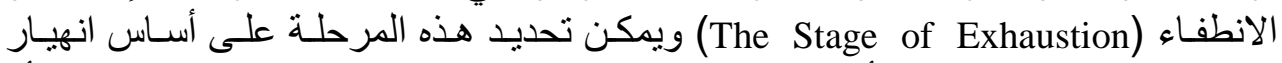

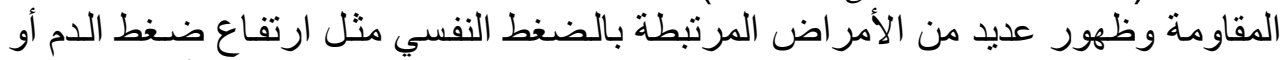

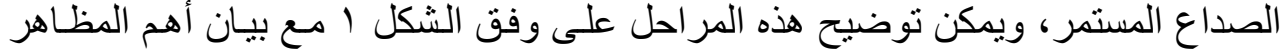
المرتبطة بكل مرحلة من المر احل. توفين.

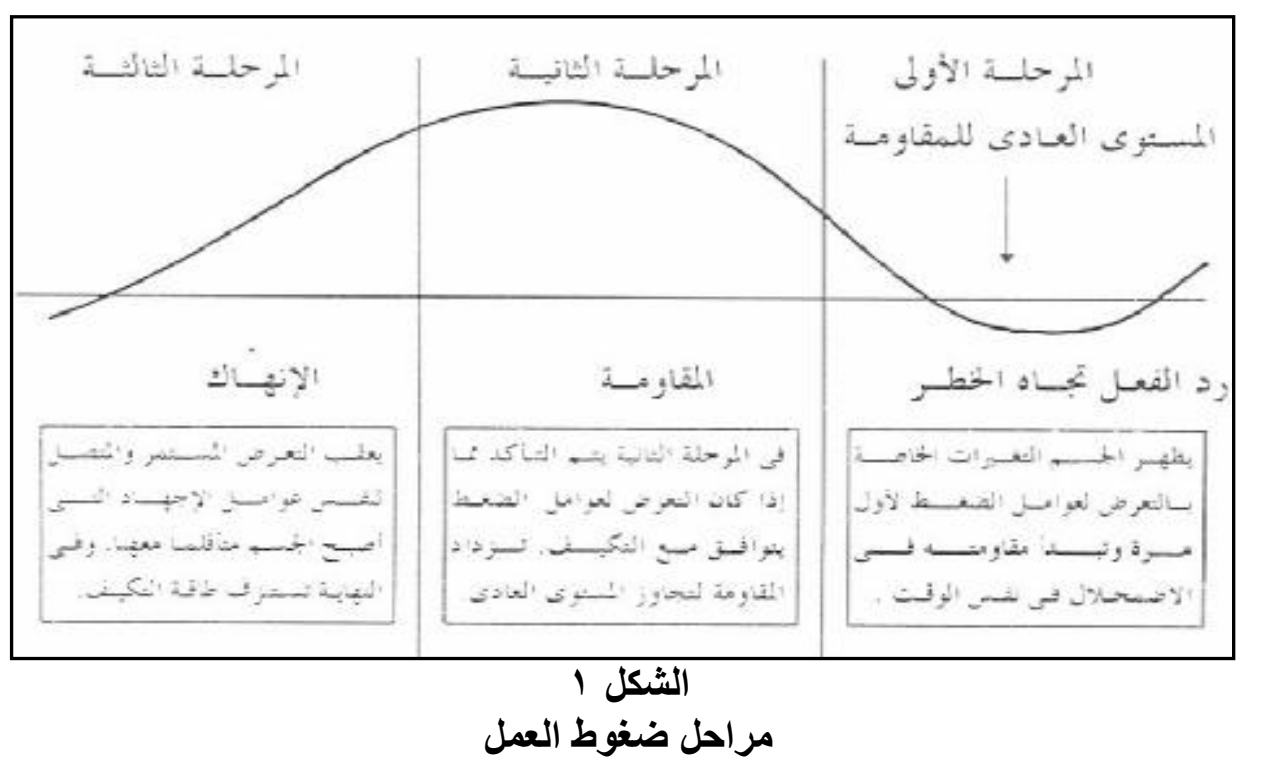

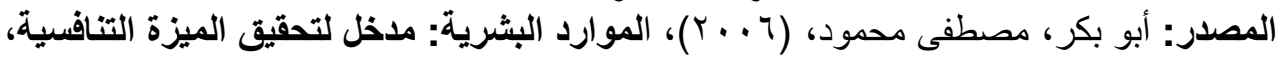

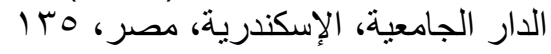

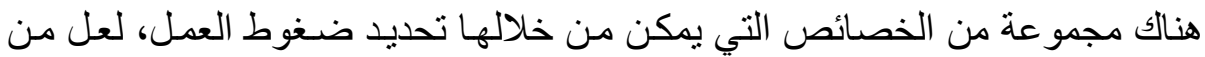
r. خصائص ضغوط العمل

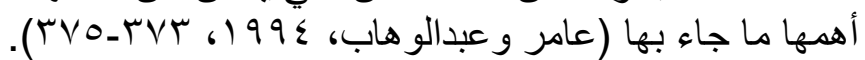

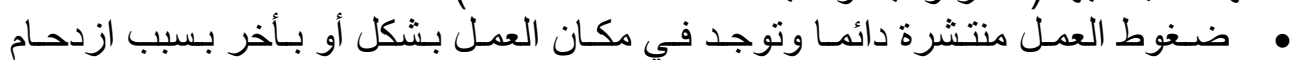

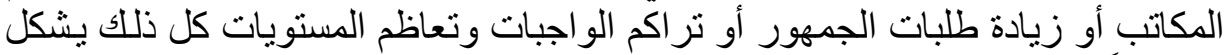

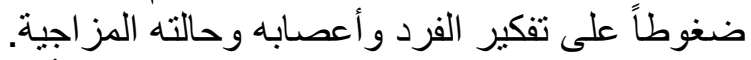

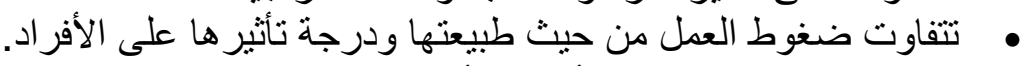

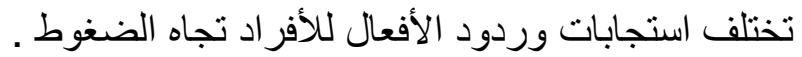

ع. أنواع ضغوط العمل

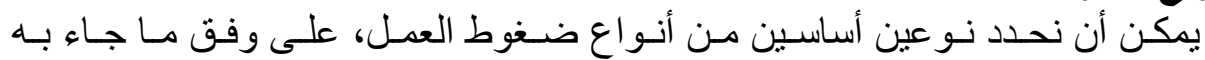

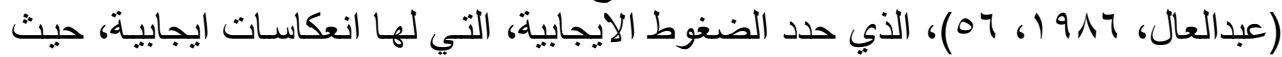

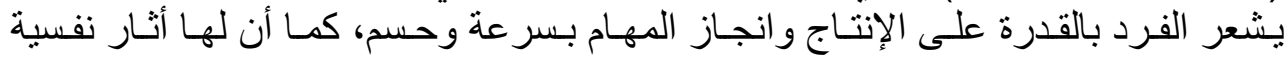

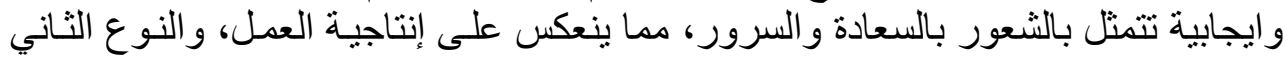
بالضغوط السلبية، المؤذيـة ذات الانعكاسـات السلبية على صحة والئل ونفسية الإنسان، ومن ثم 


\section{[1.0] أحمد}

ينعكس على أدائه و إنتاجيته في العمل، ويمكن بيان مقارنة بين النوعين المذكورين على

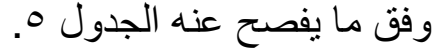

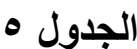

مقارنة بين أنواع ضغوط العمل

\begin{tabular}{|c|c|}
\hline الضغط السلبي & الضغط الايجابي \\
\hline يمسبِ يولد ارتباكاً في عمله الرحح المعنوية للفرد العامل & والنظر دافلى اللعل بتحد العامل وتساعده على التفكير \\
\hline 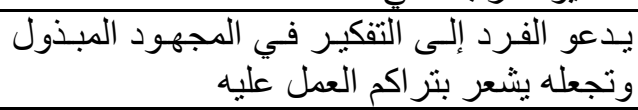 & يمنح الفرد الققرة على الثركيز على نتائج العمل \\
\hline ويشعره بالأرق و والقلق شيء يمكن أن يشوش عليه & 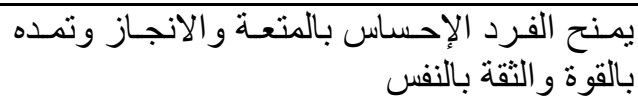 \\
\hline ألستستقبل للفرد الإحساس بالفشل و التشاؤم مـن & يمنح الفرد العامل التفاؤل بالمستقبل \\
\hline
\end{tabular}

Source: Chilly,L.,(1994), The Executive: Time and Stress Management Program Lynwood NJ: Alexander Hamilton, Institute, Inc. p155

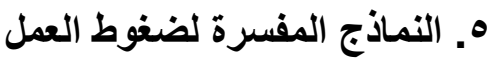

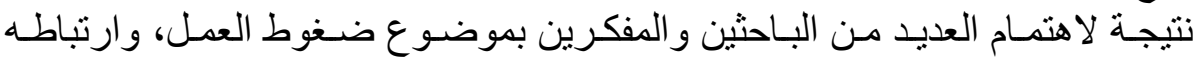
بكثير من العلوم الأخرى، إذ مثل أحد الاهتمامـات المشتركة بين المجالات الطبية الطية و النفسية

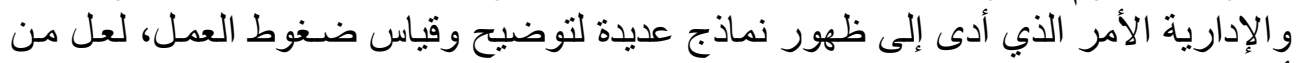

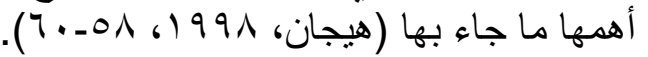

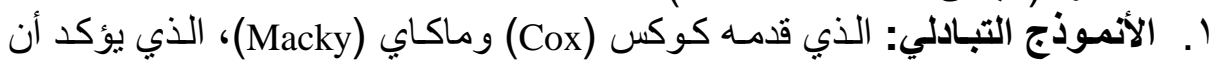

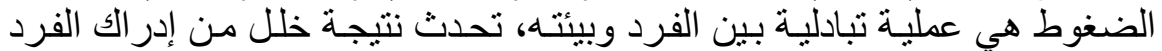

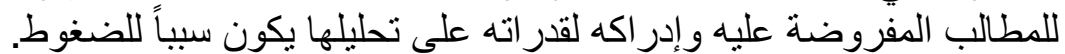

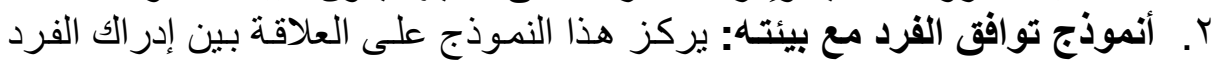

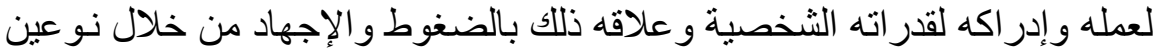

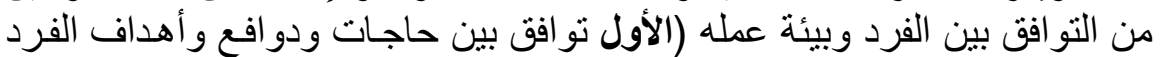

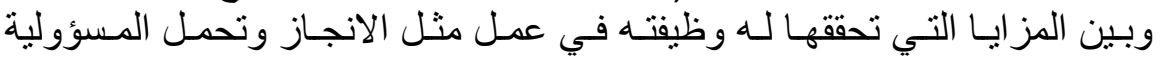

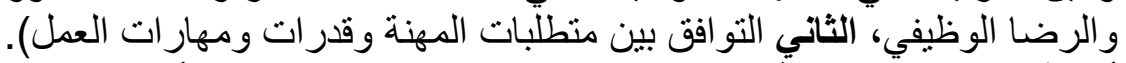
r. . أنموذج الضغوط المهنية: يتم إدر الك الموقف من قبل الفرد مـع التأكيد على تقديم

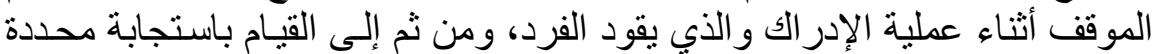

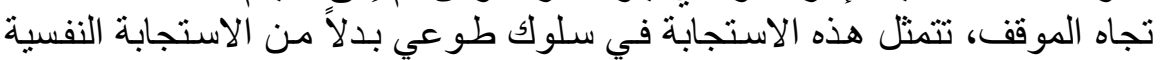
والعضوية و السلوكية. ء. أنموذج عدم التأكد: يفسر هذا الأنموذج ضـغوط العمل على أنها مـا ينعكس على ألى

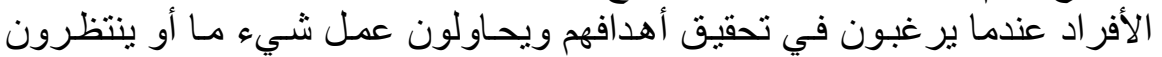

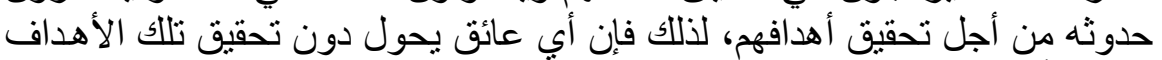

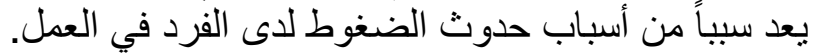


○. أنمـوذج بيرونيومـا: يركز على أن الضغوط التي يتعرض لهـا الأفراد في بيئسة

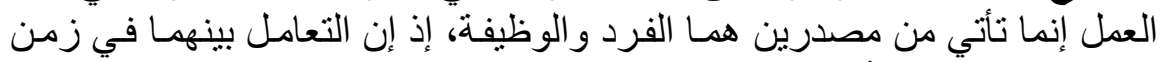

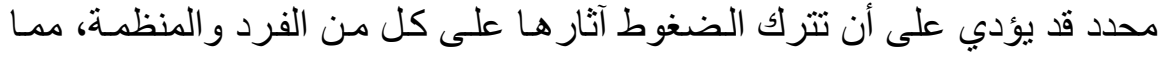

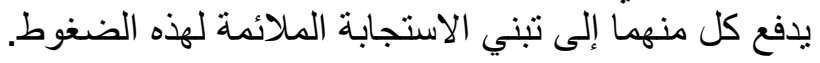

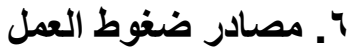

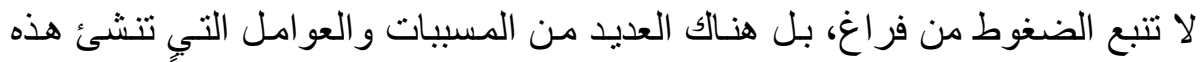

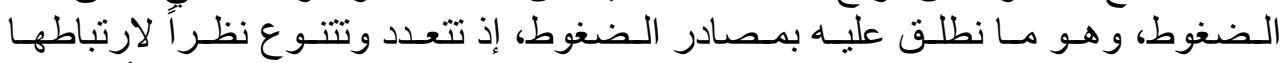

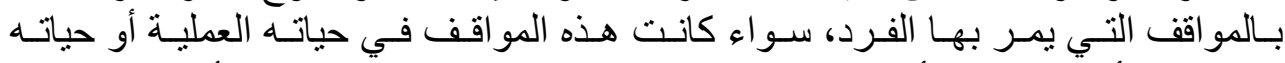

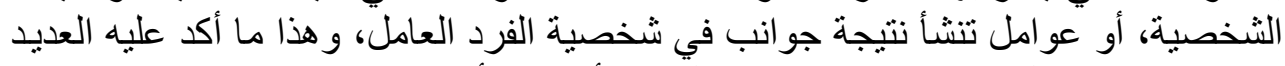

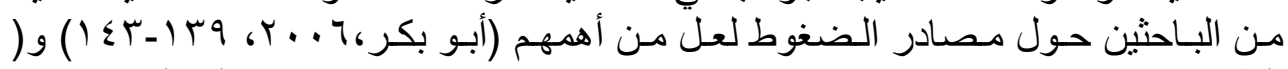

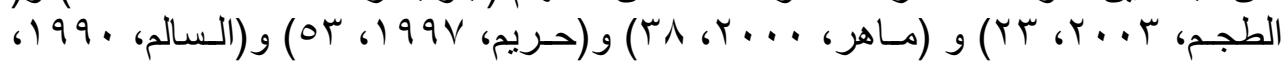

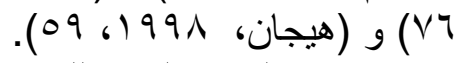

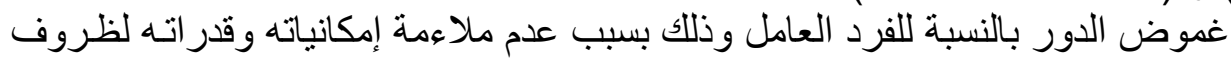

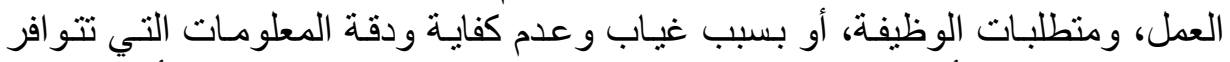

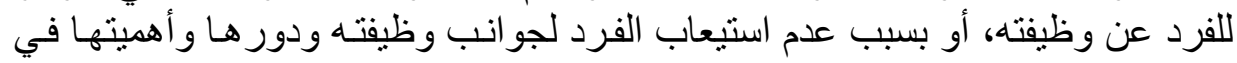

المنظمة.

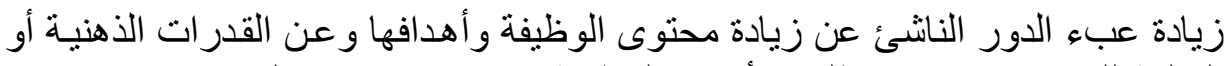

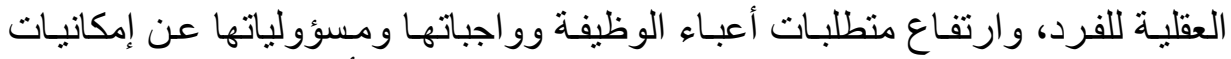

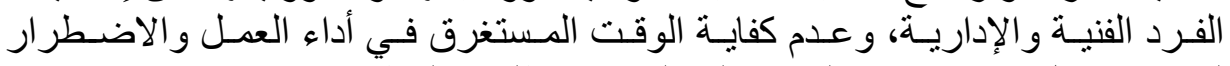

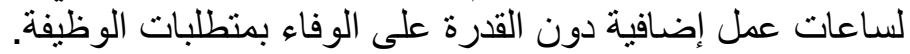

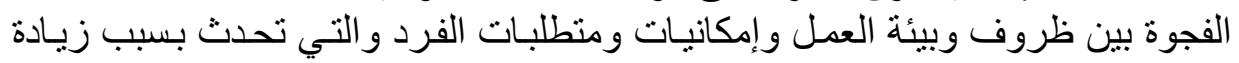

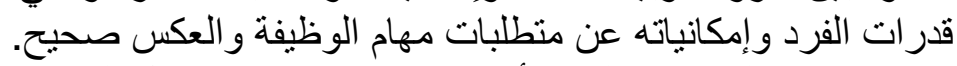

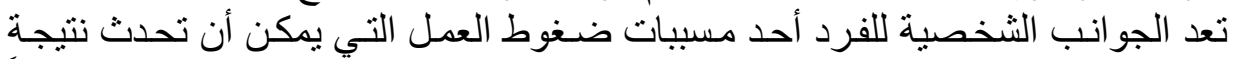

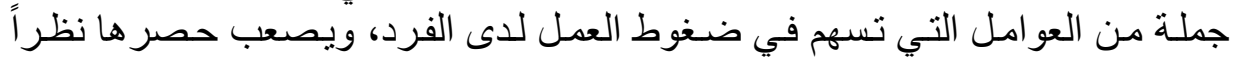

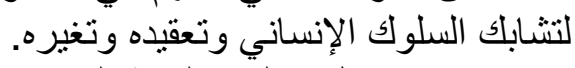

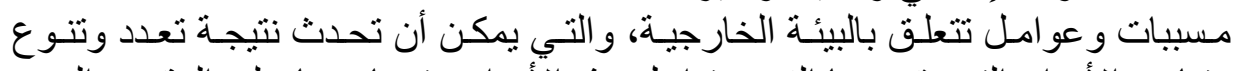

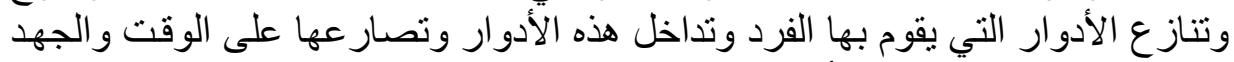

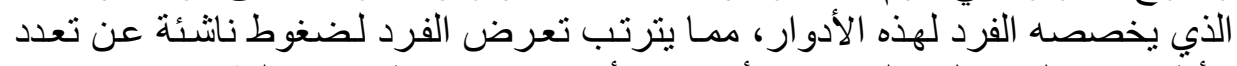



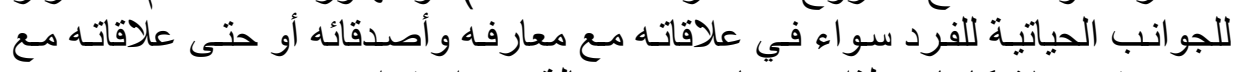

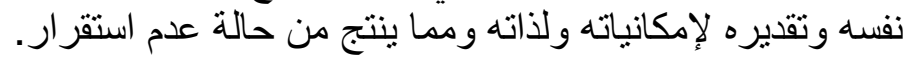

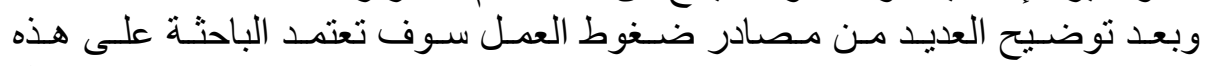

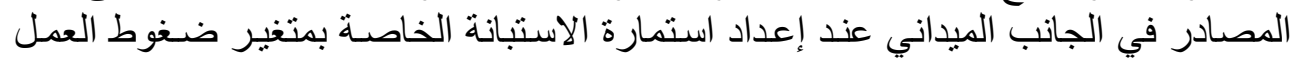

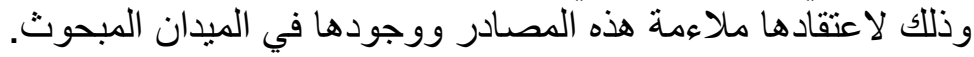


$[1 \cdot v]$

تـشير معطيـات الجدول 7 إلـى الخـصـائص العامـة بالعينـة المبحوثـة والتـي يمكن

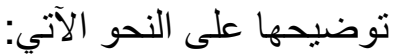

\begin{tabular}{|c|c|c|c|c|c|c|c|c|c|c|c|}
\hline \multicolumn{12}{|c|}{ أوصاف عينة البحول 7} \\
\hline \multicolumn{12}{|c|}{ الجنس } \\
\hline \multicolumn{6}{|c|}{ أنثى } & \multicolumn{6}{|c|}{ ذكر } \\
\hline \multicolumn{3}{|c|}{$\%$} & \multicolumn{3}{|c|}{$ت$} & \multicolumn{3}{|c|}{$\%$} & \multicolumn{3}{|c|}{$ت$} \\
\hline \multicolumn{3}{|c|}{$r v$} & \multicolumn{3}{|c|}{ YY } & \multicolumn{3}{|c|}{ Tr } & \multicolumn{3}{|c|}{ ז } \\
\hline \multicolumn{12}{|c|}{ العمر } \\
\hline \multicolumn{3}{|c|}{ آ فأكثر } & \multicolumn{2}{|c|}{$7 .-01$} & \multicolumn{3}{|c|}{$0 \cdot-\leqslant 1$} & \multicolumn{2}{|c|}{$\varepsilon \cdot-\mu)$} & \multicolumn{2}{|c|}{$r \cdot-r \cdot$} \\
\hline$\%$ & & $ت$ & $\%$ & ت & \multicolumn{2}{|c|}{$\%$} & & $\%$ & $ت$ & $\%$ & $ت$ \\
\hline$r$ & & 1 & $r$ & $r$ & \multicolumn{2}{|c|}{$\begin{array}{ll}\text { ro } \\
\end{array}$} & & $\varepsilon r$ & ro & IV & 1. \\
\hline \multicolumn{12}{|c|}{ المؤهل العلمي } \\
\hline \multicolumn{3}{|c|}{ دبلوم عالي } & \multicolumn{3}{|c|}{ بكالوريوس } & \multicolumn{3}{|c|}{ دبلوم فني } & \multicolumn{3}{|c|}{ إعدادية } \\
\hline$\%$ & \multicolumn{2}{|r|}{$ت$} & \multicolumn{2}{|c|}{$\%$} & $ت$ & $\%$ & \multicolumn{2}{|r|}{$ت$} & \multicolumn{2}{|c|}{$\%$} & $ت$ \\
\hline$\varepsilon$ & & $r$ & 01 & & Tr & $r^{\circ}$ & & IV & 1. & & 7 \\
\hline & & & & & غبرة & & & & & & \\
\hline كثر & & & & & & & & & & & \\
\hline$\%$ & $ت$ & $\%$ & $ت$ & $\%$ & $ت$ & $\%$ & $ت$ & $\%$ & $ت$ & $\%$ & $ت$ \\
\hline 9 & 0 & rq & IV & rᄉ & Tr & 17 & 9 & 0 & $r$ & $r$ & $r$ \\
\hline
\end{tabular}

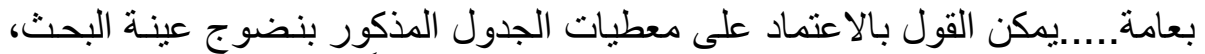

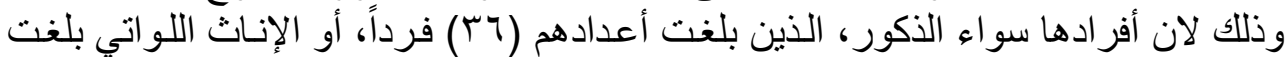

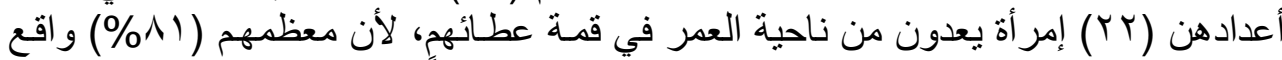

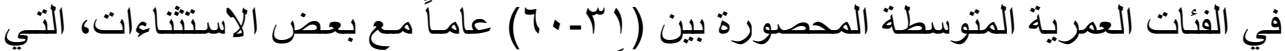

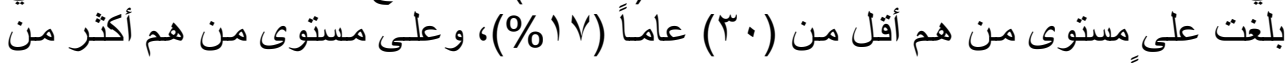

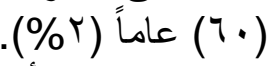

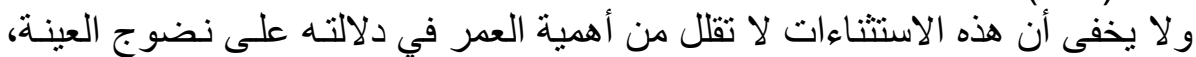

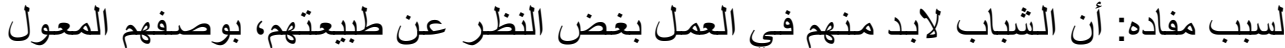

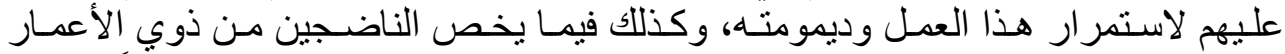

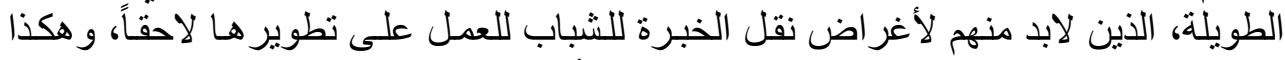

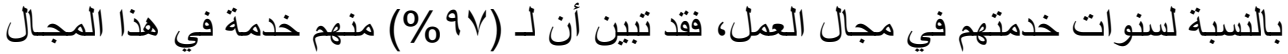

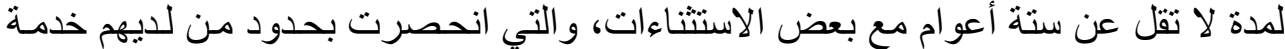

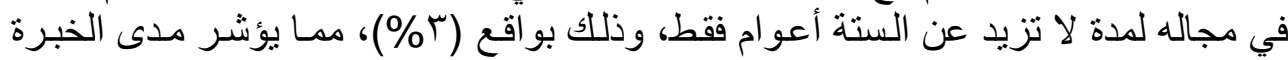

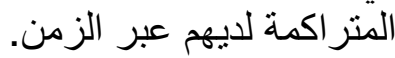

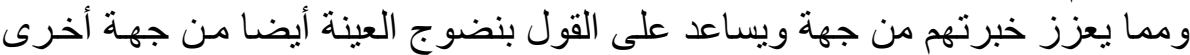

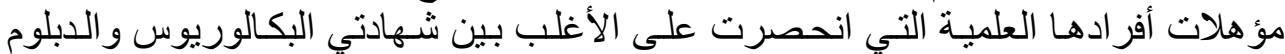

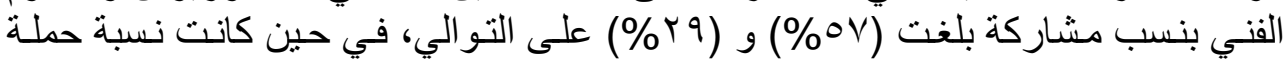

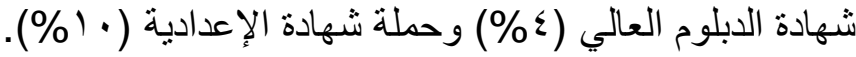


ثاتياً- مواقف المستبينة آراؤهم عن مؤشرات أبعاد الأكاء الشعوري

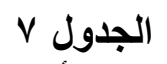

مواقف المستبينين عن أبعاد الأكاء الثعوري

\begin{tabular}{|c|c|c|c|c|c|c|c|c|}
\hline \multirow{2}{*}{ الانحرياري } & \multirow{2}{*}{ الحسابي } & \multicolumn{2}{|c|}{ لا اتفق } & \multicolumn{2}{|c|}{ محايد } & \multicolumn{2}{|c|}{ اتقق } & \\
\hline & & $\%$ & $ت$ & $\%$ & $ت$ & $\%$ & ت & \\
\hline $7 \wedge$. & T.M & $1 Y .1$ & $\bar{V}$ & $\varepsilon \varepsilon . \wedge$ & YT & $\varepsilon r .1$ & ro & $\overline{X_{1}}$ \\
\hline $7 \leq \leqslant 1$. & T.TY & 1.7 & 0 & $r \cdot . V$ & IT & $V \cdot . V$ & $\varepsilon 1$ & $\mathrm{X}_{2}$ \\
\hline$\cdot .7 \leq \varepsilon$ & r.এ9 & - & - & $1 \cdot . r$ & 7 & $19 . \mathrm{V}$ & Or & $\mathrm{X}_{3}$ \\
\hline $.7 Y \wedge$ & r.01 & - & - & $1 \cdot . r$ & 7 & 01.7 & rs & $\mathrm{X}_{4}$ \\
\hline $.7 Y \Lambda$ & r.01 & 7.9 & $\varepsilon$ & r. & YI & 07.9 & r & $\mathrm{X}_{5}$ \\
\hline. $.0 V V$ & 1.07 & \multicolumn{2}{|r|}{7.9} & \multicolumn{2}{|c|}{ rq.r } & \multicolumn{2}{|c|}{$74 . \Lambda$} & الإجمالي \\
\hline$\cdot .1177$ & r. & TY.E & $1 \pi$ & ro. 9 & 01 & $01 . V$ & $r$. & $\mathrm{X}_{6}$ \\
\hline $.09 \mathrm{~V}$ & r. & 0.1 & $r$ & $\Gamma \leqslant .0$ & $r \cdot$ & $7 \cdot . r$ & ro & $\mathrm{X}_{7}$ \\
\hline . & T.70 & 1.7 & 0 & IV.Y & 1. & $v \varepsilon .1$ & $\varepsilon r$ & $\mathrm{X}_{8}$ \\
\hline $.0 .1 \mathrm{r}$ & $r .00$ & - & - & $\varepsilon \varepsilon . \Lambda$ & ru & 00.1 & ru & $\mathrm{X}_{9}$ \\
\hline$\cdot 7 \leqslant \varepsilon$ & r.TV & 1.7 & 0 & $\varepsilon \varepsilon . \wedge$ & $r 7$ & 57.7 & TV & $X_{10}$ \\
\hline. .7491 & $Y . \leqslant \Lambda$ & \multicolumn{2}{|c|}{ rT. $\varepsilon \varepsilon$} & \multicolumn{2}{|c|}{1.97} & \multicolumn{2}{|c|}{01.10} & الإجمالي \\
\hline .041 & r.or & - & - & $\varepsilon 7.7$ & rV & or. $\varepsilon$ & M & $\mathrm{X}_{11}$ \\
\hline .07117 & $r . \Sigma 7$ & r.s & $r$ & $\varepsilon 7.7$ & TV & 0. & 19 & $X_{12}$ \\
\hline .700 & $r . \leqslant \Lambda$ & 1.7 & 0 & $r \leqslant .0$ & $r$. & 07.9 & $r$ & $X_{13}$ \\
\hline .0 .4 & $r . \Sigma 7$ & - & - & or. 5 & 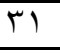 & 57.7 & TV & $\mathrm{X}_{14}$ \\
\hline$\cdot .7 \varepsilon \varepsilon$ & r.rv & 1.7 & 0 & $\Gamma \leqslant .0$ & $r \cdot$ & 70.0 & rᄉ & $\mathrm{X}_{15}$ \\
\hline$\because .0 \leqslant V Y$ & r.o & \multicolumn{2}{|c|}{ Y.E } & \multicolumn{2}{|c|}{$\varepsilon r .1 Y$} & \multicolumn{2}{|c|}{$0 \leqslant . \leqslant \Lambda$} & الإجمالي \\
\hline .070 & r.07 & - & - & r. & IT & $7 . .1$ & ro & $\mathrm{X}_{16}$ \\
\hline. .599 & $r . \Sigma T$ & - & - & 07.9 & Tr & $\varepsilon r .1$ & ro & $\mathrm{X}_{17}$ \\
\hline .0705 & $r . \Sigma T$ & r.s & $r$ & 0. & rq & $\leq 7.7$ & TV & $\mathrm{X}_{18}$ \\
\hline $.09 \pi$ & T. $\varepsilon 1$ & 0.1 & $r$ & $\varepsilon \Lambda . r$ & $r \Lambda$ & $\leq 7.7$ & TV & $\mathrm{X}_{19}$ \\
\hline.$\vee \wedge \wedge$ & Y. $\leqslant 0$ & \multicolumn{2}{|c|}{$r$} & \multicolumn{2}{|c|}{$\varepsilon V . \wedge \theta$} & \multicolumn{2}{|c|}{$\$ 9.10$} & الإجمالي \\
\hline
\end{tabular}

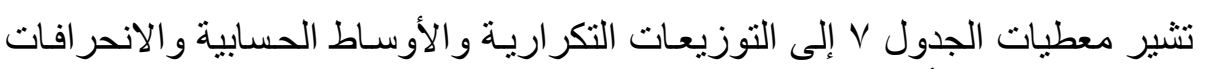

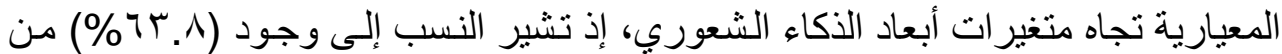

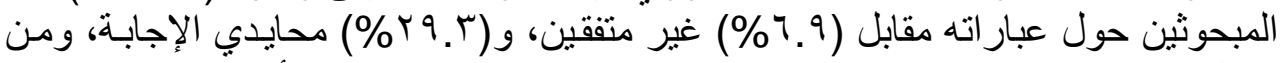

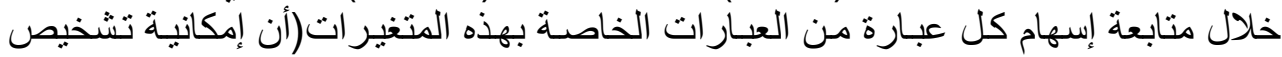

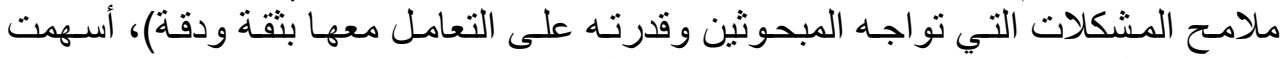

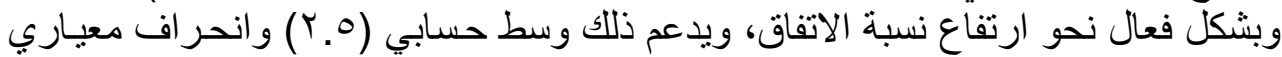

$$
\text { .(. . OV V })
$$

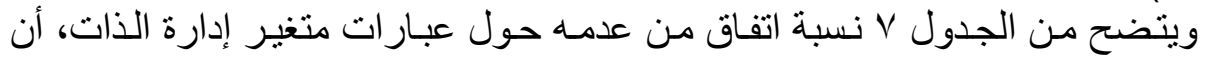

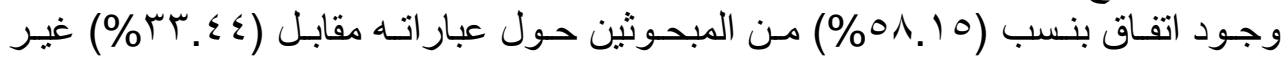




\section{[1.9] أحمد}

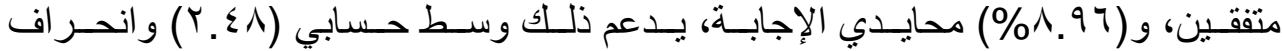

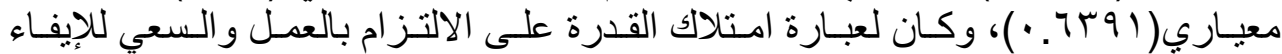

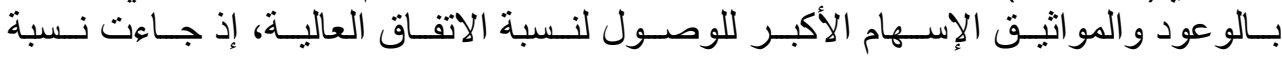

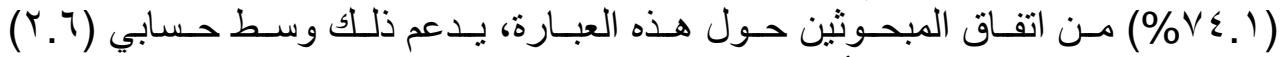

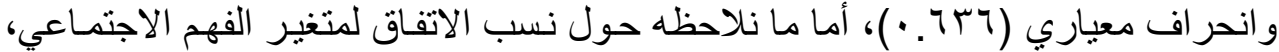

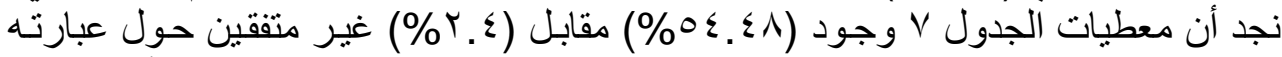

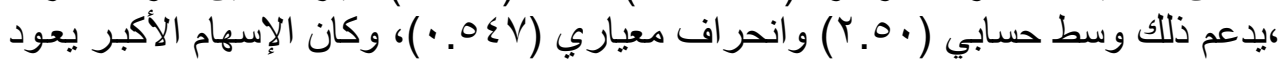

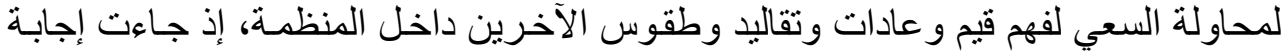

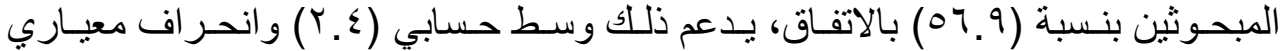

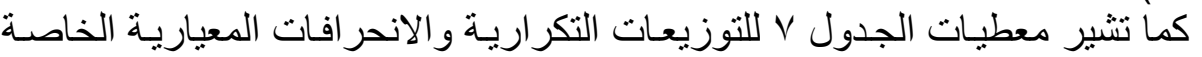

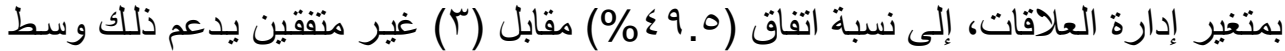

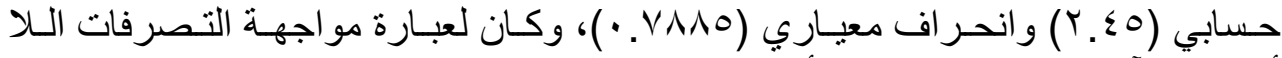

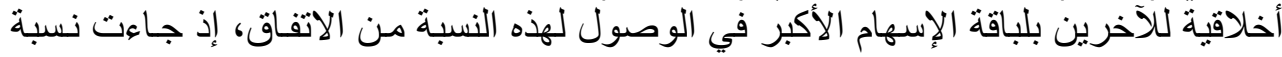

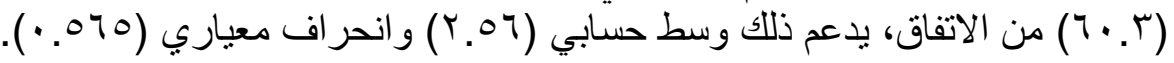

ثالثاً. مواقف المستبينة آراؤهم عن مؤشرات متغير ضغوط العمل

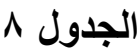

مواقف المستبينين من ضغوط العمل

\begin{tabular}{|c|c|c|c|c|c|c|c|c|}
\hline \multirow{2}{*}{ المعياري } & \multirow{2}{*}{ الحسابي } & \multicolumn{2}{|c|}{ لا اتفق } & \multicolumn{2}{|c|}{ محايد } & \multicolumn{2}{|c|}{ اتفق } & \multirow{2}{*}{ المتغيرات } \\
\hline & & $\%$ & 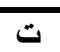 & $\%$ & $\ddot{ت}$ & $\%$ & $ت$ & \\
\hline. $.9 r r$ & $T .10$ & rद. & $\overline{Y I}$ & $T .1$ & $\bar{V}$ & $01 . V$ & $r$. & $\overline{X_{20}}$ \\
\hline$\cdot . \wedge K M I$ & 1.10 & $\varepsilon \wedge . r$ & TA & TV.T & 17 & $r \varepsilon .1$ & $1 \varepsilon$ & $\overline{X_{21}}$ \\
\hline$. . \wedge 9 \leq$ & $1 . V Y$ & 07.9 & $r$ & $1 \pi .1$ & $\wedge$ & rq.r & IV & $X_{22}$ \\
\hline.$\wedge \mu r$ & $1 . V Y$ & $01 . V$ & $r$. & $r \varepsilon .1$ & $1 \varepsilon$ & $r \varepsilon .1$ & $1 \varepsilon$ & $\overline{X_{23}}$ \\
\hline$\cdot \wedge T \varepsilon$ & $\overline{T . Y \varepsilon}$ & $T V . T$ & 17 & $r \cdot . V$ & $T$ & $01 . V$ & $r$. & $\mathrm{X}_{24}$ \\
\hline. $.0 \vee \wedge$ & T.70 & $01 . V$ & $r$. & $r \varepsilon .1$ & $1 \varepsilon$ & $r \xi .1$ & $1 \varepsilon$ & $\overline{X_{25}}$ \\
\hline.$\wedge I V$ & $1 . V V$ & $\leq 7.7$ & $T V$ & $r q . r$ & IV & $r \varepsilon .1$ & $1 \varepsilon$ & $\overline{X_{26}}$ \\
\hline$\cdot .71$. & Y.71 & $1 Y .1$ & $V$ & 7.9 & $\varepsilon$ & 11.1 & $\varepsilon V$ & $X_{27}$ \\
\hline .7 .1 & T.VO & 1.7 & 0 & 7.9 & $\varepsilon$ & $\lambda \leqslant .0$ & $\leqslant 9$ & $\mathrm{X}_{28}$ \\
\hline .1999 & $\overline{Y . Y Y}$ & $r \leqslant .0$ & $r$. & $\varepsilon 1 . \varepsilon$ & $r \xi$ & $r \leqslant .1$ & $1 \varepsilon$ & $\overline{\mathrm{X}_{29}}$ \\
\hline .1870 & 1.19 & ro.9 & 10 & $r V .7$ & 17 & $\leq 7.7$ & $T V$ & $\overline{X_{30}}$ \\
\hline$\cdot . \wedge \mu r$ & $r . r^{\prime}$ & $7 T^{2} 1$ & $r 7$ & $1 \pi .1$ & $\wedge$ & $r \Sigma .1$ & $1 \varepsilon$ & $\overline{X_{31}}$ \\
\hline
\end{tabular}




\begin{tabular}{|c|c|c|c|c|c|c|c|c|}
\hline$\therefore .10 \leqslant$ & $1.7 \%$ & $7 r .1$ & ry & $1 \pi .1$ & $\lambda$ & $r \varepsilon .1$ & $T \varepsilon$ & $\mathrm{X}_{32}$ \\
\hline$\therefore \vee \vee \neg \wedge$ & r.rv & $T V . r$ & 1. & TV.T & 17 & $00 . r$ & $\overline{r r}$ & $\overline{X_{33}}$ \\
\hline$\therefore$ VरTV & T.RV & 19 & 11 & $r \varepsilon .0$ & $r$. & $\leqslant 7.7$ & $\overline{T V}$ & $\mathrm{X}_{34}$ \\
\hline$\cdot .9 . V$ & 1.17 & $\varepsilon \Lambda . r$ & TA & $I V . Y$ & 1. & $r \varepsilon .0$ & $r$. & $\mathrm{X}_{35}$ \\
\hline$\because \vee \vee \wedge \varepsilon$ & Y.YO & $r \cdot . V$ & $T r$ & $r r_{. \Lambda}$ & 19 & 57.7 & $r V$ & $X_{36}$ \\
\hline$\cdot .119$ & T.IV & ro. & 10 & r.. & 11 & $\varepsilon r .1$ & ro & $\mathrm{X}_{37}$ \\
\hline$\cdot \wedge \wedge \wedge$ & 1.91 & $r q . V$ & $r \mu$ & $r r_{. \varepsilon}$ & $\pi$ & $r v .9$ & $r r$ & $\mathrm{X}_{38}$ \\
\hline$\cdot .211$ & r.11 & \multicolumn{2}{|c|}{ rr.r. } & \multicolumn{2}{|c|}{ Yo.Vq } & \multicolumn{2}{|c|}{$\varepsilon \cdot .91$} & الإجمالي \\
\hline
\end{tabular}

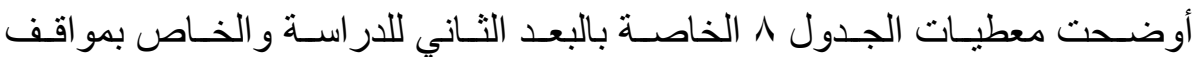
المستبينين من ضغوط العمل، إذ أنثارت معطياته إلى النسب التس التكر اريـة و الأوسـاط الحسابية

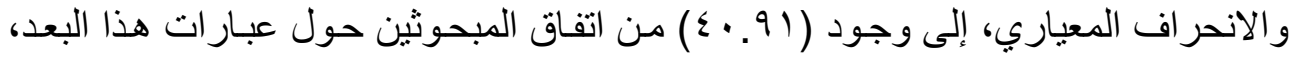

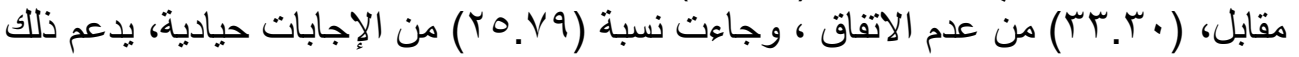

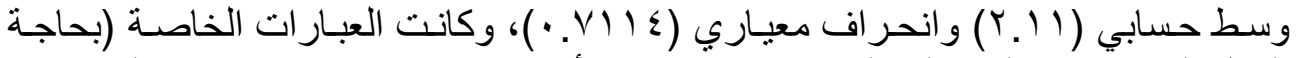

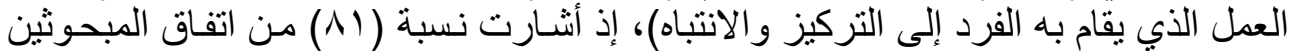

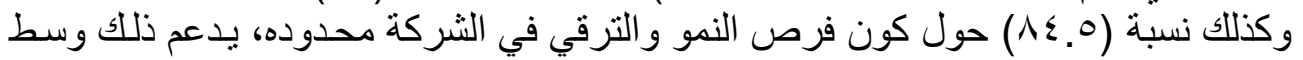

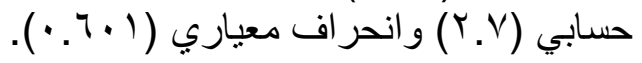

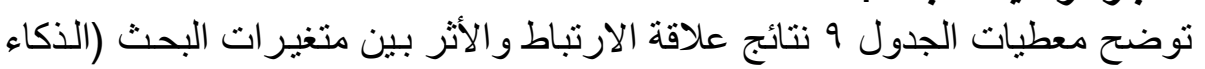
الشعوري وضغوط العمل)، إذ تم استخدام البرنامج الإحصائي (SPSS).

\section{الجدول 9}

نتائج علاقة الارتباط والأثر لمتغيرات البحث

\begin{tabular}{|c|c|c|c|c|c|}
\hline \multicolumn{5}{|c|}{ الذكاء الثعوري } & \\
\hline المؤشر الكلي & إدارة العلاقات & الفهم الاجتماعي & إدارة الذات & فهم الذات & \\
\hline $\begin{array}{c}{ }^{*} \mathrm{R}=0.938 \\
\mathrm{R}^{2}=0.50 \\
\mathrm{~F}=59.47 \\
\mathrm{SIG}=0.00\end{array}$ & $\begin{array}{c}{ }^{*} \mathrm{R}=0.910 \\
\mathrm{~B}=0.55 \\
\mathrm{~T}=6.15 \\
\mathrm{SIG}=0.01\end{array}$ & $\begin{array}{c}{ }^{*} \mathrm{R}=0.730 \\
\mathrm{~B}=0.30 \\
\mathrm{~T}=5.43 \\
\mathrm{SIG}=0.00\end{array}$ & $\begin{array}{c}{ }^{*} \mathrm{R}=0.891 \\
\mathrm{~B}=0.54 \\
\mathrm{~T}=3.953 \\
\mathrm{SIG}=0.04\end{array}$ & $\begin{array}{c}{ }^{*} \mathrm{R}=0830 \\
\mathrm{~B}=0.31 \\
\mathrm{~T}=4.622 \\
\mathrm{SIG}=0.04\end{array}$ & ضغوط العمل \\
\hline
\end{tabular}

$$
\mathrm{P}<0.05
$$

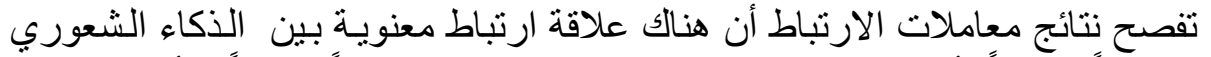

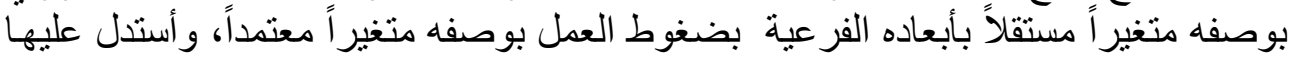

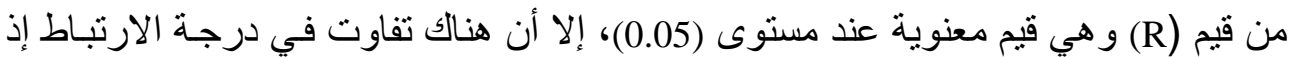
أن المؤشر الكلي أرتبط بأعلى درجة بضغوط العمل، وبهذا تحققت الفرضية الأولى. 


\section{[111] أحمد}

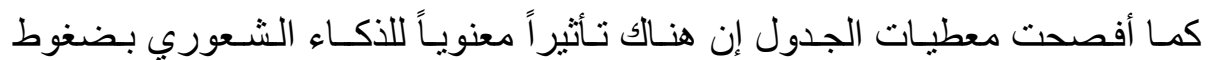

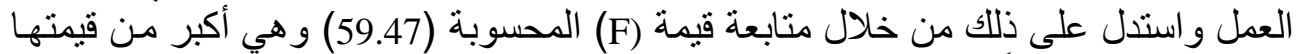

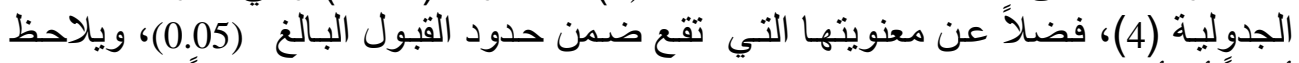

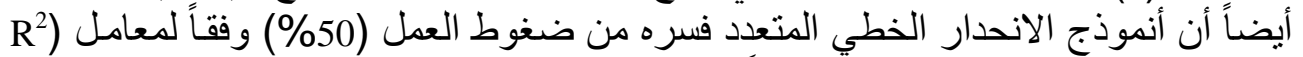

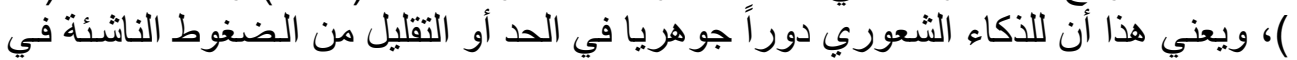

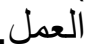

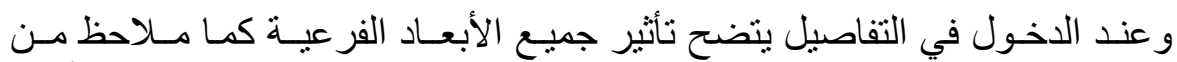

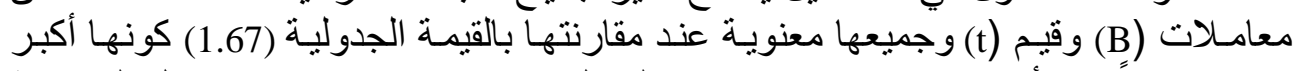

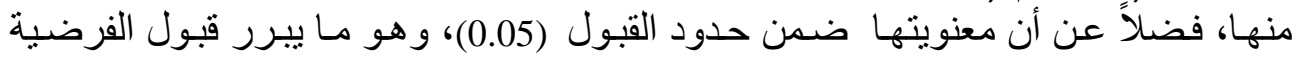
الثانية.

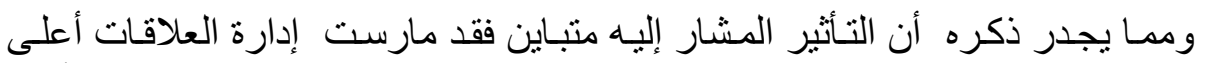

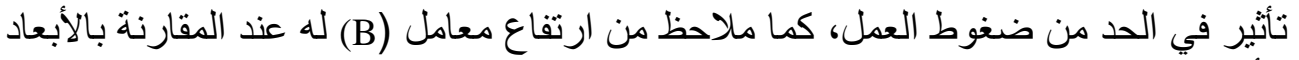
الأخرى، وهو ما يحقق ثبوت الفرضية الفيل الثالثة.

الاستتناجات والتوصيات

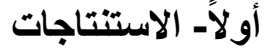

بعـد المعالجـة النظريـة و الميدانيـة لمسشكلة البحــث يمكـن الخـروج بالاسـتنتاجات و التوصيات الآتية:

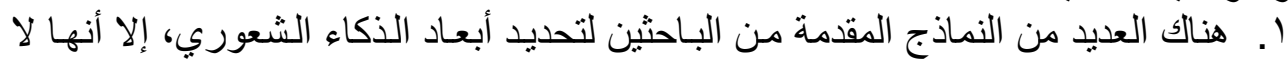

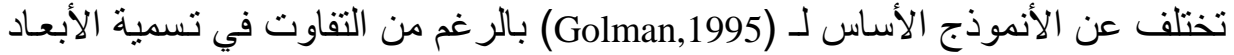

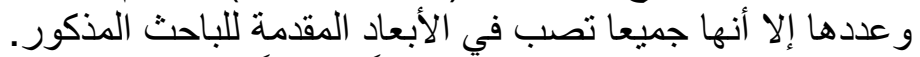

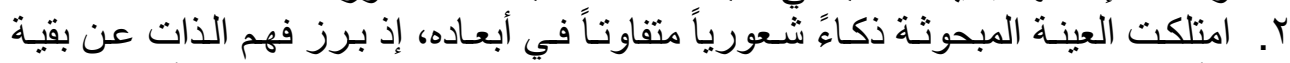

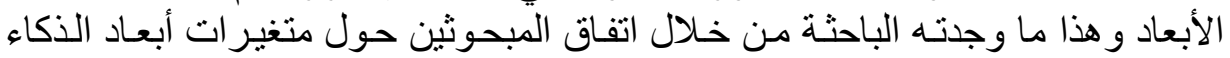
الثعوري، وربما يعود ذللك إلى ارتفاع أعمار المبحوثين، مما يعني خوضهم العديد من التهن

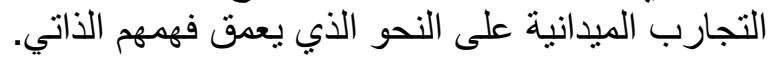

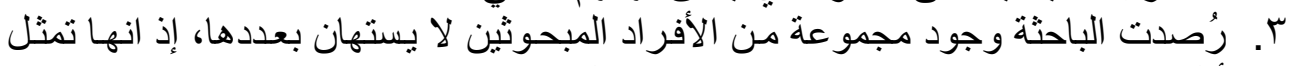

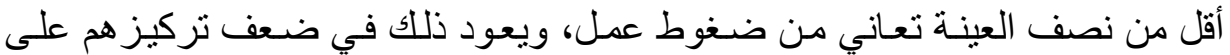

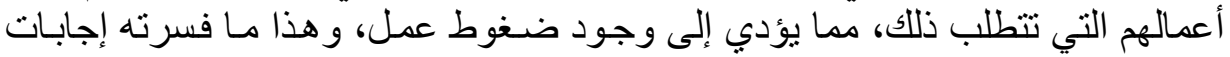

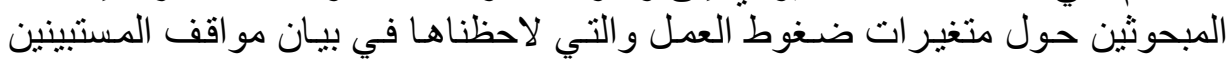
حول ضغوط العمل.

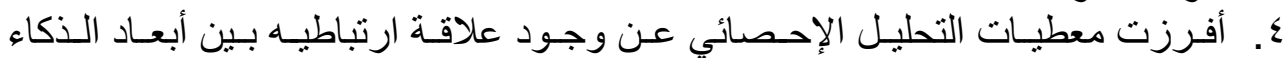

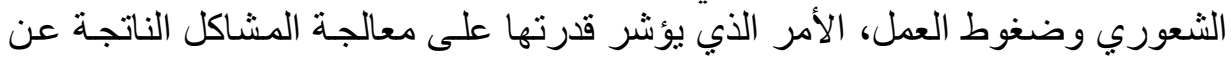
ضغوط التمل.

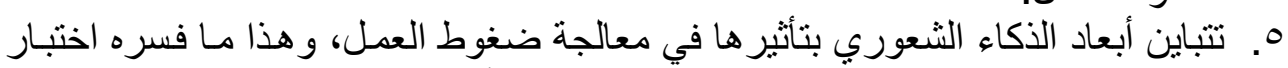
الفرضية، ومرد ذلك إلى التباين في امتلاك العينة لا أبعاد هذا الذكاء.

ثانياً- التوصيات

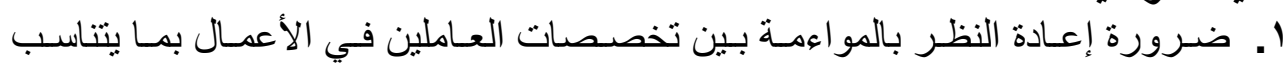
وقدر اتهم ومؤ هلاتهم. 


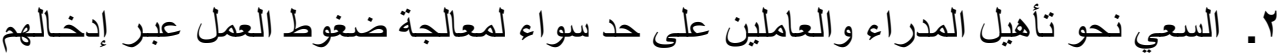

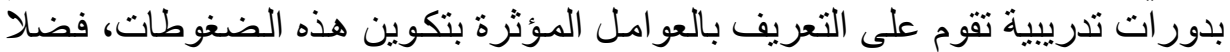
عن آلية معالجتها.

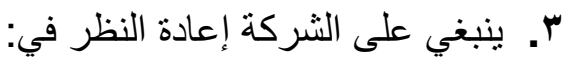

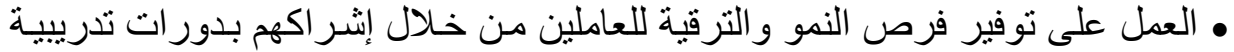

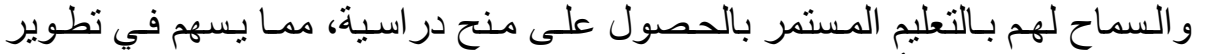
مقدرة العاملين على أداء مهام متعددة.

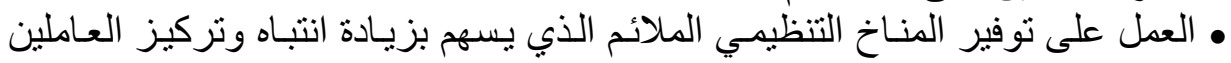
بإعمالهم. • العمل على تحديد حجم الأعمال الموكلة إليهم. • توحبد السياسات والإرشادات بشكل تكون متو افقة من قبل مصدري الأوري الأوامر.

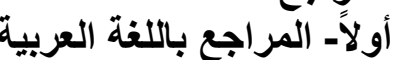

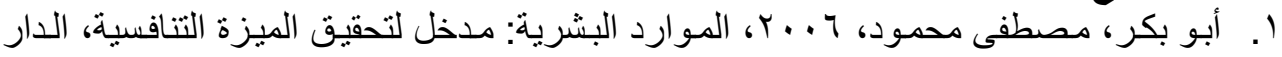

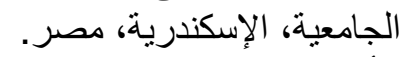

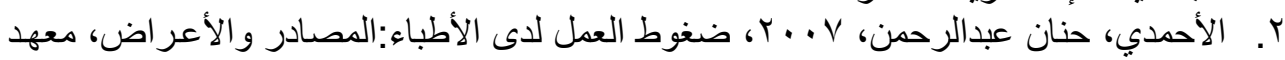

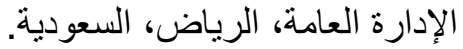

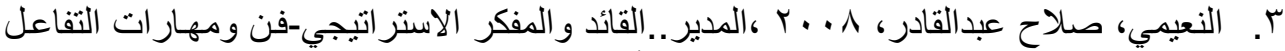

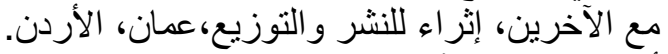

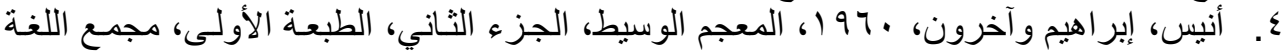

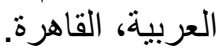

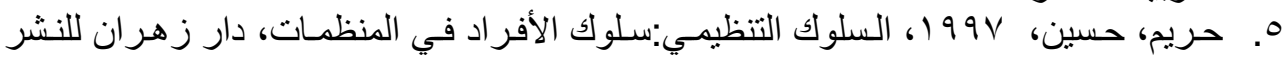

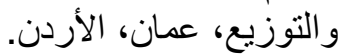

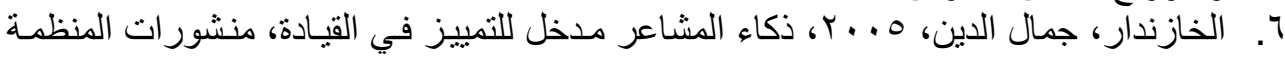

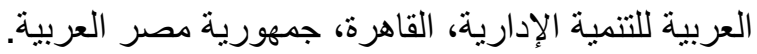

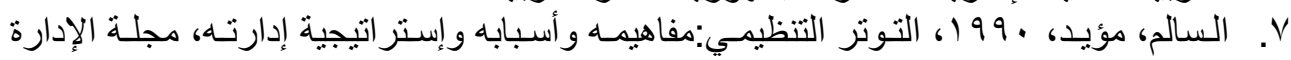

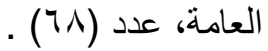

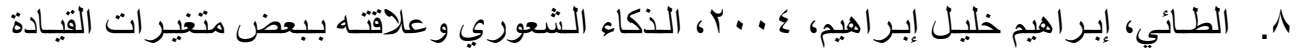

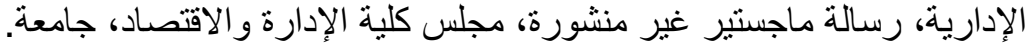

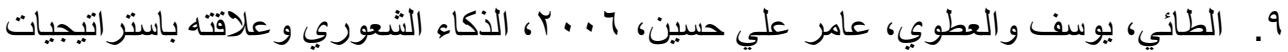

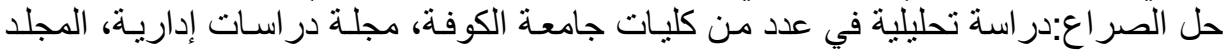

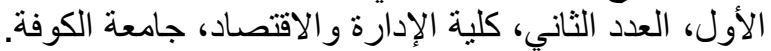

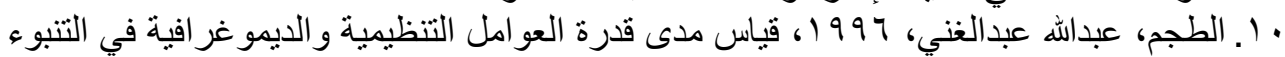

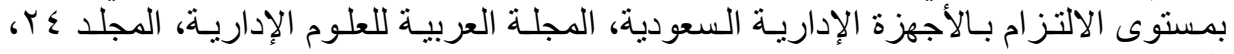
العدد (1) (1).

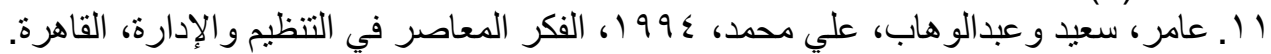

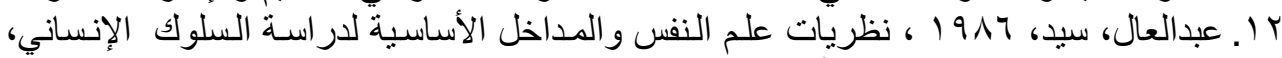

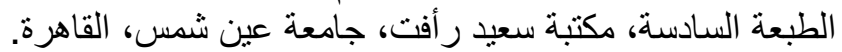

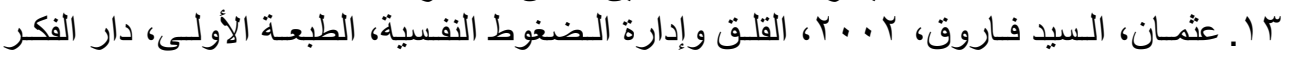




\section{[11, أحمد]}

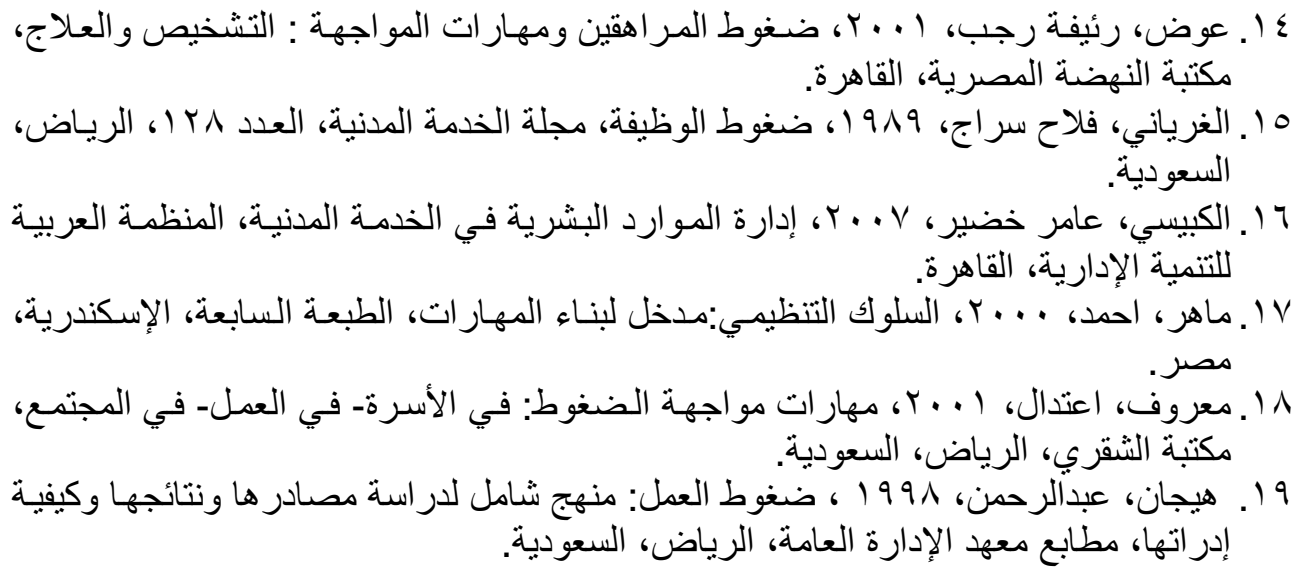

\section{ثانياً. المراجع باللغة الأجنبية}

1. Bar-On, R., 1997, Bar-On Emotional Quotient Inventory (EQ-i): technical manual. Toronto, Canada: Multi-Health Systems..

2. Brust, B.W.,2001, Emotional Intelligence: Leaders Guide, www.crmlearning.com

3. Chilly,L.,1994, The Executive :Time and Stress Management Program Lynwood NJ: Alexander Hamilton, Institute, Inc.

4. Curro, Michells,2009, Does Student Leadership Participation Enhance the Development of Emotional Intelligence, A thesis Perusal Presented to the Faculty of the California Polytechnic State University, San Luis, obisopo. www.obisopo.com

5. Goleman D. 1998, Working with Emotional Intelligence. Bloomsbury, London.

6. Goleman, D.,1995, Emotional Intelligence. New York: Bantom Books.

7. Kostka, Katia, (S.D), The Benefits Emotional Intelligence in Copies Reciting and Leadership Management, A capstone project, University of Denver, www.denver.com

8. Marsland, K.W. and Likavec, S.C., 2003, Maternal emotional intelligence, infant attachment and child socio-emotional competence. Paper presented at the 15th Annual Meeting of the American Psychological Society ,Atlanta, GA.

9. Mayer, J.D. and Salovey, P., 1997, What is emotional intelligence? In P. Salovey and D. Sluyter (eds.): Emotional development and emotional intelligence: educational implications pp. 3-31. New York: Basic Books.

10. Mayer, J.D., Caruso, D., and Salovey, P. 1999. Emotional intelligence meets traditional standards for an intelligence. Intelligence, 27, 267-298.

11. Mayer, J.D., Salovey, P., and Caruso, D., 2000), Models of emotional intelligence. In R.J. Sternberg (ed.): Handbook of human intelligence. New York: Cambridge University Press.

12. Orma,Geetuand Cannon,K., 2000,every thing you wanted to know about implementing on EQ programs: Getting stared, Competency and Emotional Intelligence, Quarterly, $\operatorname{Vol}(8), \operatorname{No}(4)$, Autumn.

13. Stys,Y.and Brown,L.,2004, A Review of the Emotional Intelligence Literature and Implication for Corrections, www.jobfunction.bnet.com 